\title{
Comparative analysis of Mycobacterium and related Actinomycetes yields insight into the evolution of Mycobacterium tuberculosis pathogenesis
}

\author{
Abigail Manson McGuire ${ }^{1,9^{*}}$, Brian Weiner ${ }^{1}$, Sang Tae Park ${ }^{4}$, Ilan Wapinski ${ }^{1,8}$, Sahadevan Raman ${ }^{4}$, \\ Gregory Dolganov ${ }^{6}$, Matthew Peterson $^{3}$, Robert Riley ${ }^{2}$, Jeremy Zucker ${ }^{1}$, Thomas Abeel ${ }^{1,5}$, Jared White ${ }^{1}$, Peter Sisk ${ }^{1}$, \\ Christian Stolte', Mike Koehrsen ${ }^{1}$, Robert T Yamamoto ${ }^{7}$, Milena lacobelli-Martinez ${ }^{7}$, Matthew J Kidd', \\ Andreia M Maer ${ }^{7}$, Gary K Schoolnik ${ }^{6}$, Aviv Regev ${ }^{1}$ and James Galagan ${ }^{1,3,4}$
}

\begin{abstract}
Background: The sequence of the pathogen Mycobacterium tuberculosis (Mtb) strain H37Rv has been available for over a decade, but the biology of the pathogen remains poorly understood. Genome sequences from other Mtb strains and closely related bacteria present an opportunity to apply the power of comparative genomics to understand the evolution of Mtb pathogenesis. We conducted a comparative analysis using 31 genomes from the Tuberculosis Database (TBDB.org), including 8 strains of Mtb and M. bovis, 11 additional Mycobacteria, 4 Corynebacteria, 2 Streptomyces, Rhodococcus jostii RHA1, Nocardia farcinia, Acidothermus cellulolyticus, Rhodobacter sphaeroides, Propionibacterium acnes, and Bifidobacterium longum.

Results: Our results highlight the functional importance of lipid metabolism and its regulation, and reveal variation between the evolutionary profiles of genes implicated in saturated and unsaturated fatty acid metabolism. It also suggests that DNA repair and molybdopterin cofactors are important in pathogenic Mycobacteria. By analyzing sequence conservation and gene expression data, we identify nearly 400 conserved noncoding regions. These include 37 predicted promoter regulatory motifs, of which 14 correspond to previously validated motifs, as well as 50 potential noncoding RNAs, of which we experimentally confirm the expression of four.

Conclusions: Our analysis of protein evolution highlights gene families that are associated with the adaptation of environmental Mycobacteria to obligate pathogenesis. These families include fatty acid metabolism, DNA repair, and molybdopterin biosynthesis. Our analysis reinforces recent findings suggesting that small noncoding RNAs are more common in Mycobacteria than previously expected. Our data provide a foundation for understanding the genome and biology of Mtb in a comparative context, and are available online and through TBDB.org.
\end{abstract}

Keywords: Comparative genomics, M. tuberculosis, SYNERGY, Small RNAs, Lipid metabolism, Molybdopterin, DNA repair

\section{Background}

Tuberculosis is still a major killer worldwide, causing an estimated 2-3 million deaths per year [1]. The sequence of the pathogen Mycobacterium tuberculosis $(M t b)$ strain $H 37 R v$ has been available for a decade [2,3], but the biology of the pathogen remains poorly understood. Available genome sequences from $M t b$ strains and other closely

\footnotetext{
* Correspondence: amcguire@broadinstitute.org

${ }^{1}$ Broad Institute, 7 Cambridge Center, Cambridge, MA 02142, USA Full list of author information is available at the end of the article
}

related Mycobacteria present an opportunity to bring the power of comparative genomics to the study of $M t b$.

We report here the results of a comparative analysis of 31 publicly available genomes (http://www.tbdb.org, Figure 1, Table 1). These include eight closely related members of the $M t b$ complex that can cause tuberculosis disease, (two M. bovis strains and six Mtb strains). Another 11 additional Mycobacteria range from obligate parasites to free-living soil bacteria: $M$. leprae and M. avium subsp. Paratuberculosis K10, the causative

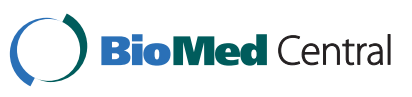

(c) 2012 McGuire et al; licensee BioMed Central Ltd. This is an Open Access article distributed under the terms of the Creative Commons Attribution License (http://creativecommons.org/licenses/by/2.0), which permits unrestricted use, distribution, and reproduction in any medium, provided the original work is properly cited. 


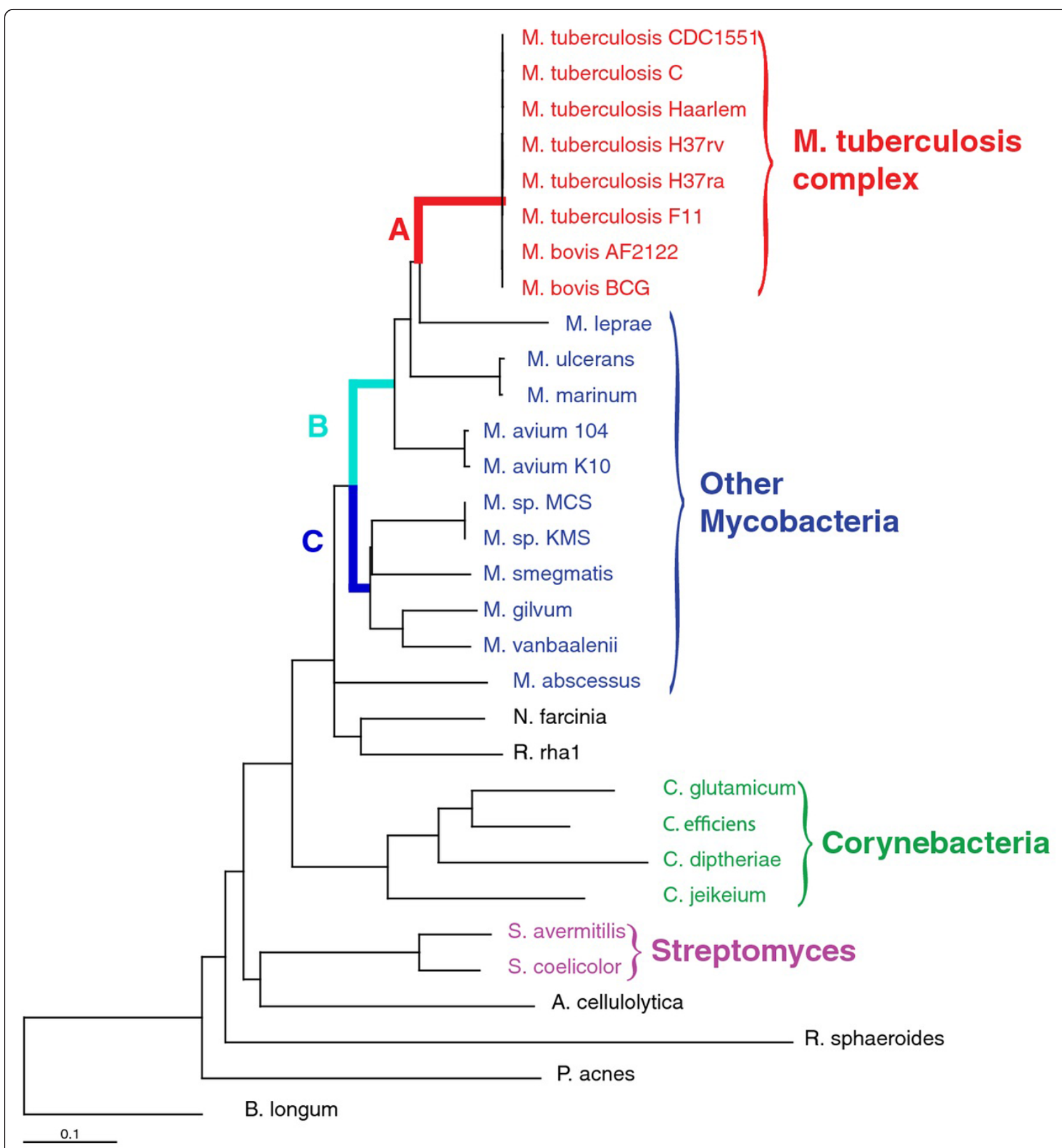

Figure 1 Phylogenetic Tree based on uniform SYNERGY orthogroups, scaled by phylogenetic distance. The labels A-C indicate the branches selected for further analysis in our $d_{N} / d_{S}$ analysis (A: The branch leading to the Mtb cluster; B: The branch leading to the pathogenic Mycobacteria; $C$ : The branch leading to the non-pathogenic, soil-dwelling Mycobacteria). See Methods for details on the phylogenetic tree construction.

agents of leprosy and paratuberculosis respectively, are pathogenic and require hosts to survive; $M$. ulcerans, $M$. marinum, M. avium 104, and M. abscessus have the potential to be pathogenic but can survive outside the confines of a host; M. vanbaalenii, M. sp. KMS, M. sp. $M C S$, and M. gilvum are free-living soil bacteria which are known to degrade a variety of compounds including polycyclic aromatic hydrocarbons (PAH), and are useful in bioremediation efforts. Thus, the Mycobacteria included in our dataset span an ecological range from host-dependent pathogens to soil bacteria, allowing us to study multiple evolutionary transitions. 
Table 1 Summary of Organisms

\begin{tabular}{|c|c|c|c|c|}
\hline Organism & $\begin{array}{l}\text { Patho- } \\
\text { genic }\end{array}$ & $\begin{array}{l}\text { Host } \\
\text { required }\end{array}$ & Description & Reference \\
\hline $\begin{array}{l}\text { Mycobacterium tuberculosis } \\
\text { H37RV }\end{array}$ & Y & Y & Causes TB; Laboratory strain & [2] \\
\hline $\begin{array}{l}\text { Mycobacterium tuberculosis } \\
\text { H37Ra }\end{array}$ & Y & Y & Causes TB; Avirulent sister strain to H37Rv & [4] \\
\hline $\begin{array}{l}\text { Mycobacterium tuberculosis F11 } \\
\text { (ExPEC) }\end{array}$ & Y & Y & Causes TB; isolated from TB patient in S. Africa & [5] \\
\hline $\begin{array}{l}\text { Mycobacterium bovis BCG str. } \\
\text { Pasteur } 1173 P 2\end{array}$ & Y & Y & Causes bovine TB; attenuated vaccine strain & [6] \\
\hline Mycobacterium bovis AF2122/97 & Y & Y & Causes bovine TB & [7] \\
\hline $\begin{array}{l}\text { Mycobacterium tuberculosis } \\
\text { Haarlem }\end{array}$ & Y & Y & Causes TB; MDR strain & [5] \\
\hline Mycobacterium tuberculosis C & Y & Y & Causes TB; isolated in NY City & [5] \\
\hline $\begin{array}{l}\text { Mycobacterium tuberculosis } \\
\text { CDC1551 }\end{array}$ & Y & Y & Causes TB; highly contagious \& virulent strain & [8] \\
\hline Mycobacterium ulcerans AGY99 & Y & & Causes Buruli ulcer & [9] \\
\hline Mycobacterium marinum & $\mathrm{Y}$ & & From fish; Skin lesions in human & {$[10]$} \\
\hline Mycobacterium leprae TN & Y & Y & Causes leprosy & [11] \\
\hline Mycobacterium avium 104 & Y & & Opportunistic pathogen; can causeTB-type pulmonary infection & [12] \\
\hline $\begin{array}{l}\text { Mycobacterium avium subsp. } \\
\text { Paratuberculosis K-10 }\end{array}$ & Y & Y & Causes paratuberculosis; obligate pathogen of cattle & [13] \\
\hline Mycobacterium sp. MCS & & & Soil bacteria; degrades PAH & [14] \\
\hline Mycobacterium sp. KMS & & & Soil bacteria; degrades PAH & [14] \\
\hline $\begin{array}{l}\text { Mycobacterium smegmatis } \\
\text { MC2155 }\end{array}$ & Y & & $\begin{array}{l}\text { Widely used model for Mtb isolated from human smegma; causes soft tissue } \\
\text { lesions }\end{array}$ & {$[12]$} \\
\hline Mycobacterium vanbaalenii PYR-1 & & & Soil bacteria; degrades $\mathrm{PAH}$ & [14] \\
\hline Mycobacterium gilvum & & & Soil bacteria; Degrades PAH + wide variety of organic compounds & [14] \\
\hline Mycobacterium abscessus & Y & & Skin \& soft tissue infections & [15] \\
\hline Rhodococcus jostii RHA1 & & & $\begin{array}{l}\text { Soil bacteria important for biofuels research and bioremediation; degrades PCB } \\
+ \text { wide variety of organic compounds }\end{array}$ & {$[16]$} \\
\hline Nocardia farcinica IFM 10152 & Y & & Causes nocardiosis & {$[17]$} \\
\hline $\begin{array}{l}\text { Corynebacterium glutamicum } \\
\text { ATCC } 13032\end{array}$ & & & Produces amino acids (Glu) & [18] \\
\hline Corynebacterium efficiens YS-314 & & & Produces amino acids (Glu) & [19] \\
\hline $\begin{array}{l}\text { Corynebacterium diphtheriae } \\
\text { NCTC13129 }\end{array}$ & Y & & Causes diphtheria & [20] \\
\hline Corynebacterium jeikeium K411 & Y & & Causes nocosomial infections & {$[21]$} \\
\hline Streptomyces avermitilis MA-4680 & & & Soil bacteria;antibiotic-producing & [22] \\
\hline Streptomyces coelicolor A3(2) & & & Soil bacteria;antibiotic producing & {$[23]$} \\
\hline Acidothermus cellulolyticus $11 B$ & & & Hot springs of Yellowstone & [24] \\
\hline Rhodobacter sphaeroides & & & Gram -, motile; photosyn.; fixes $N_{2}$ & {$[14]$} \\
\hline $\begin{array}{l}\text { Propionibacterium Acnes } \\
\text { KPA171202 }\end{array}$ & Y & & Causes acne & [25] \\
\hline Bifidobacterium Longum NCC2705 & & & Digestive track commensal; yogurt & {$[26]$} \\
\hline
\end{tabular}

To gain further insight into the Mycobacterium cluster, we also included a related Rhodococcus (also involved in bioremediation), a pathogenic Nocardia, four Corynebacteria (two pathogens and two that are commercially useful in amino acid production), two
Streptomyces (antibiotic-producing soil bacteria), Acidothermus cellulolyticus (a thermophilic actinobacteria from the hot springs of Yellowstone), Propionibacterium acnes (causative agent of common acne), and Bifidobacterium longum (a digestive track commensal often found 
in yogurt). We extend this comparative analysis to other more distantly related Actinobacteria to yield additional insight into evolutionary trends.

We examined protein evolution across these 31 organisms, both at the nucleotide level and at the level of protein families, including studying gene families associated with the transition from nonpathogenic soil-dwelling bacteria to obligate pathogens. Our results highlight the importance of lipid metabolism and its regulation, and reveal differences in the evolutionary profiles for genes implicated in saturated and unsaturated fatty acid metabolism. Our analysis also suggests that DNA repair and molybdopterin cofactors are expanded in pathogenic Mycobacteria and $M t b$.

We also identified highly conserved elements within noncoding regions using whole-genome multiple alignments and gene expression data. These conserved elements include 37 predicted conserved promoter regulatory motifs, of which 14 correspond to previously reported motifs. They also include approximately 50 predicted novel noncoding RNAs. Guided by our computational analysis, we tested and experimentally confirmed the expression of 4 novel small RNAs in $M t b$.

The results of our analyses are available on our website, and provide a foundation for understanding the genome and biology of $M t b$ in a comparative context.

\section{Results and discussion}

\section{An orthogroup catalogue for Mycobacteria}

We used SYNERGY $[27,28]$ to reconstruct the phylogeny of proteins across all 31 organisms, define sets of orthologs ("orthogroups"), and construct a phylogenetic tree of the genomes (Figure 1). An orthogroup is defined as the set of genes descended from a single common ancestral gene in the last common ancestor of the species under consideration [28], containing both orthologs and possibly paralogs (Methods). At each node in the phylogenetic tree, we tabulated orthogroup appearances, duplications, and losses (Figure 2). Figure 2 gives an overview of the evolution of gene families within these species. Full listings of the events tabulated in Figure 2, as well as additional information about each orthogroup, can be found on the Supplementary Information website:

\section{Tracing the evolution of biological processes}

To examine the evolution of entire pathways and gene families, we categorized orthogroups according to GO (Gene Ontology) and GO Slim terms [29], PFAM domains [30], metabolic pathways, predicted regulons (sets of genes predicted to be regulated by a common regulatory protein), and groups of genes upregulated under certain lipids (Methods). We also looked for orthogroups undergoing positive selection by calculating the ratio of nonsynonymous to synonymous mutations (the $d_{N} / d_{S}$ ratio). Figure 3 shows several examples of pathway or gene family profiles and the predicted evolutionary events associated with the gene family. The sort of graphic presented in Figure 3 is browsable for every pathway, PFAM, and GO term in our Supplementary Information website. Tables 2 and 3 show the PFAM and GO categories most expanded (with the most orthogroup members) in the $M t b$ clade relative to the non-pathogenic Mycobacteria, and Tables 4 and 5 show those most expanded in the Mycobacteria relative to the nonMycobacteria.

\section{Substantial expansion of known pathogenicity and lipid metabolism genes}

Despite the smaller genome sizes present in the pathogenic Mycobacteria, and the resulting background of orthogroup loss in the evolution towards pathogens, we observe significant expansions in certain gene families in the pathogenic Mycobacteria and the $M t b$ complex relative to non-pathogenic relatives. We also observe evidence for selection in certain families on branches leading to the pathogenic Mycobacteria, the Mtb complex, and the soildwelling Mycobacteria.

As expected, many genes known to be related to pathogenicity or antigenic variability are among the groups most expanded in the $M t b$ clade relative to soil dwelling Mycobacteria as well as being among the categories with the most variability in copy number in their category-level profiles overall, including toxin-antitoxin genes, genes containing PE (Pro-Glu) and PPE (Pro-Pro-Glu) domains, MCE (Mammalian Cell Entry) genes, genes involved in the synthesis of the mycolic acid coat, Esx genes, and gene involved in antibiotic resistance. Complete results for all groupings are available on our Supplementary Information website. Below we focus on specific additional families showing noteworthy expansions and trends.

The single most significant trend in our analysis of protein family evolution is that genes related to lipid metabolism are greatly expanded across all Mycobacteria and related organisms, consistent with previous observations $[2,31]$ (Table 5). Our analysis extends these previous observations by identifying the emergence of this expansion in lipid metabolism genes as occurring at the root node of the Mycobacteria and Rhodococcus (Figure 3).

\section{Particular expansion of saturated fatty acid metabolism and lipid synthesis genes in pathogenic Mycobacteria} Genes predicted to be involved in the metabolism of saturated fatty acids are more expanded than those involved in the metabolism of unsaturated fatty acids. Using a compendium of microarray expression experiments (Methods), we compiled a list of genes upregulated in the presence of different fatty acid sources. We found that genes upregulated under unsaturated conditions have 


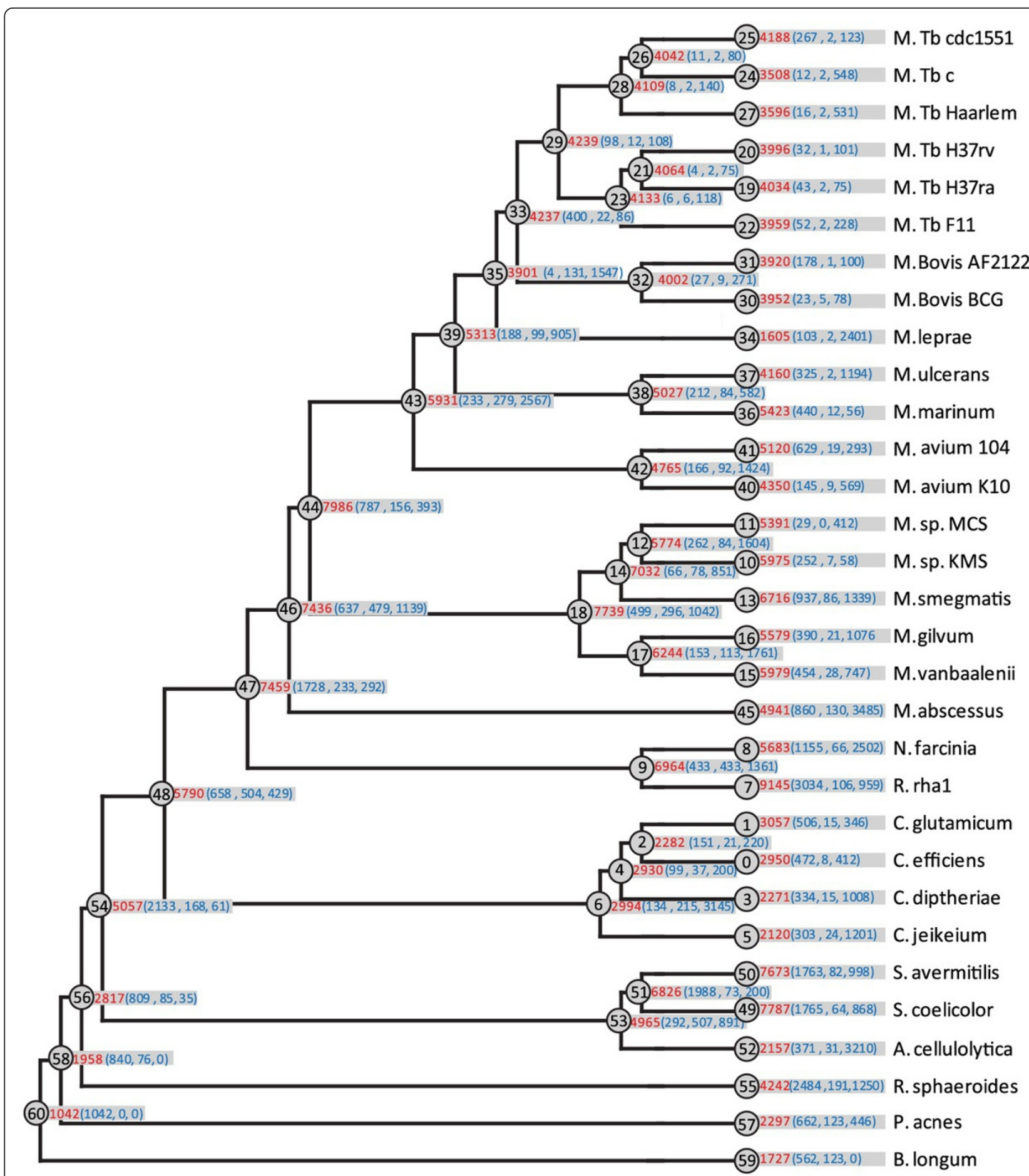

Figure 2 Summary of SYNERGY results: Number of gains, losses, and duplication at each node. For each node, the node number is marked in black; the total number of genes present at each node is indicated in red, and the numbers of gains, losses, and duplications are indicated in parenthesis in blue http://www.broadinstitute.org/ftp/pub/seq/msc/pub/SYNERGY/index.html.

more uniform phylogenetic profiles, while those upregulated under saturated conditions, cholesterol or ceramide have expanded through duplications in pathogenic Mycobacteria (Figure 4). Saturated fatty acids and cholesterol are more prevalent in an animal host than in the soil, which contains mostly unsaturated fatty acid from plant inputs. Since it is believed that $M t b$ uses cholesterol as a carbon source within the host [32], this could reflect an 


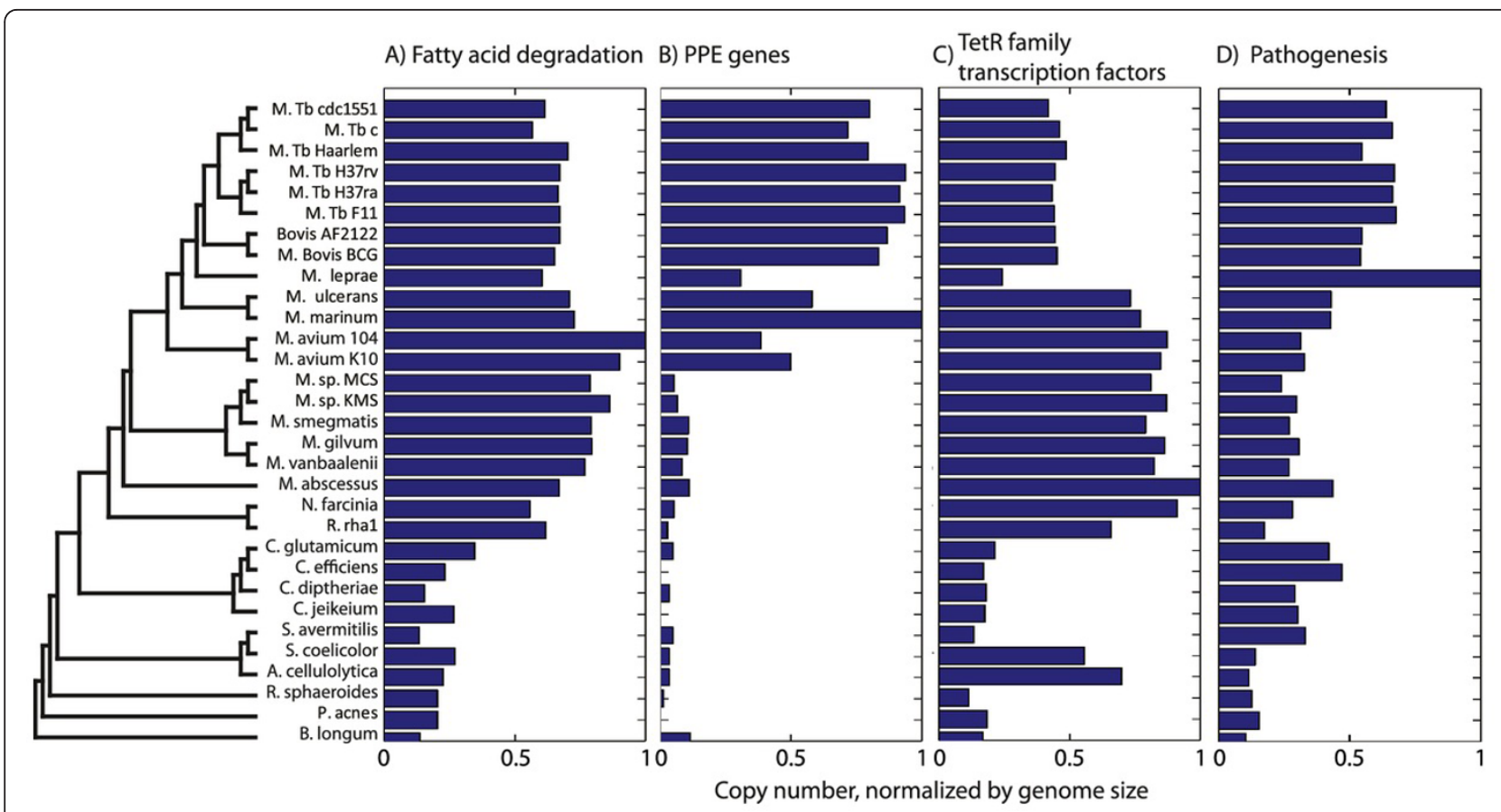

Figure 3 Evolution of gene categories. This figure shows several examples of the evolution of metabolic pathways, PFAM domains, and GO term descriptors. Graphics similar to these can be found for each category in the supplementary information website at http://www. broadinstitute.org/ftp/pub/seg/msc/pub/SYNERGY/index.html. a) Fatty acid degradation metabolic pathway. b) PFAM group PF00823 (PPE genes). c) PFAM group PF00440 (tetR family transcription factors). d) GO term 0009405 (pathogenesis.)

adaptation to the host environment. Consistent with our observations in host-adapted Mycobacteria, Desulfovibrio desulfuricans intestinal strains contain a higher ratio of saturated to unsaturated fatty acids than soil strains of Desulfovibrio desulfuricans [33].

Our analysis also reveals differences in evolutionary profiles between genes predicted to be involved in catabolism and anabolism of lipids. Both sets of genes are expanded in soil-dwelling and pathogenic Mycobacteria, but lipid synthesis genes are additionally expanded in pathogens relative to soil dwellers. General lipid synthesis genes are expanded across the Mycobacteria, but certain groups of lipid synthesis genes, including those related to cell wall synthesis, are further expanded in the $M t b$ complex (see Supplementary Information). In pathogenic Mycobacteria, the waxy mycolic acid coat helps evade the host immune system [34]. Consistent with this, we see categories related to mycolic acid synthesis showing up among the most non-uniform categories, highly expanded in the $M t b$ complex (see Supplementary Information).

In contrast, some lipid degradation gene families are more expanded in the soil-dwelling Mycobacteria than in the pathogens (Supplementary Data). The soil-dwellers have the unusual ability to degrade a vast array of compounds, including diverse lipids.
Positive selection of lipid metabolism genes

In addition to gene family expansions, we observe evidence for selection on the coding sequence of lipid metabolism genes. In our $\mathrm{d}_{\mathrm{N}} / \mathrm{d}_{\mathrm{S}}$ calculations, we observe enrichment for positive selection in lipid degradation genes on the branch leading to the pathogenic Mycobacteria (Additional file 1: Table S2). For example, Rv2524c, the multifunctional FAS-I polypeptide utilized during de novo fatty synthesis [35], has the second highest $\mathrm{d}_{\mathrm{N}} / \mathrm{d}_{\mathrm{S}}$ value on this branch. Additional lipid metabolism genes with elevated $d_{N} / d_{S}$ values include 15 genes predicted to be involved in the $\beta$-oxidation pathway of fatty acid degradation: seven $f a d E$ (acyl coA dehydrogenase) genes, three $f a d D$ (fatty acid CoA ligase) genes, two $f a d B$ (NADPH quinone oxidoreductase/3-hydroxybutyryl-CoA dehydrogenase) genes, one fadA (acetyl-CoA acyltransferase) gene, and two echA (enoyl-CoA hydratase) genes. Hence, we observe expansions of lipid biosynthesis genes, as well as observing evidence for positive selection acting on genes within the $\beta$-oxidation pathway. Both the lipid biosynthesis and lipid degradation pathways are specialized within the pathogenic Mycobacteria. This expansion could possibly benefit the pathogen in a manner to accommodate production and modification of cell wall lipids involved in manipulation of host immune response. The lipid degradation is particularly beneficial for the 
Table 250 PFAM categories most expanded in the Mtb clade relative to the non-pathogenic, soil-dwelling Mycobacteria

\begin{tabular}{|c|c|c|c|}
\hline PFAM name & PFAM ID & p-value ${ }^{a}$ & $\begin{array}{l}\text { inter-to-intra- } \\
\text { centroid difference }\end{array}$ \\
\hline${ }^{\mathrm{b}} \mathrm{PIN}$ domain & PF01850 & 4.20E-09 & $1.10 \mathrm{E}+01$ \\
\hline GHMP kinases $C$ terminal & PF08544 & 1.00E-08 & $8.80 \mathrm{E}+00$ \\
\hline DHHA1 domain & PF02272 & $2.10 \mathrm{E}-08$ & $6.80 \mathrm{E}+00$ \\
\hline KGG Stress-induced bacterial acidophilic repeat motif & PF10685 & $6.70 \mathrm{E}-08$ & $6.20 \mathrm{E}+00$ \\
\hline b Protein of unknown function (DUF1396) (lipoproteins within cell wall) & PF07161 & 4.10E-07 & $9.20 \mathrm{E}+00$ \\
\hline b Rv0623-like transcription factor (toxin-antitoxin-related) & PF07704 & 9.30E-07 & $1.00 \mathrm{E}+01$ \\
\hline Tetratricopeptide repeat & PF07720 & 9.90E-07 & $8.60 \mathrm{E}+00$ \\
\hline PA domain & PF02225 & $1.00 \mathrm{E}-06$ & $6.40 \mathrm{E}+00$ \\
\hline ` Patatin-like phospholipase & PF01734 & $1.20 \mathrm{E}-06$ & $9.20 \mathrm{E}+00$ \\
\hline e Protein of unknown function (DUF1490) & PF07371 & $1.20 \mathrm{E}-06$ & $1.00 \mathrm{E}+01$ \\
\hline 4 FAD binding domain & PF01565 & $1.30 \mathrm{E}-06$ & $6.40 \mathrm{E}+00$ \\
\hline Fumarate reductase/succinate dehydrog. flavoprotein C-term domain & PF02910 & $1.50 \mathrm{E}-06$ & $5.90 \mathrm{E}+00$ \\
\hline FIST C domain & PF10442 & $2.00 \mathrm{E}-06$ & $1.20 \mathrm{E}+01$ \\
\hline Corticotropin ACTH domain & PF00976 & $2.30 \mathrm{E}-06$ & $6.00 \mathrm{E}+00$ \\
\hline c Beta-ketoacyl synthase, N-terminal domain & PF00109 & $2.40 \mathrm{E}-06$ & $5.00 \mathrm{E}+00$ \\
\hline IlvB leader peptide & PF08049 & 4.20E-06 & $3.50 \mathrm{E}+00$ \\
\hline c Beta-ketoacyl synthase, C-terminal domain & PF02801 & $4.50 \mathrm{E}-06$ & $4.80 \mathrm{E}+00$ \\
\hline${ }^{\mathrm{c}}$ Acyl transferase domain & PF00698 & 4.60E-06 & $5.20 \mathrm{E}+00$ \\
\hline b PPE family (antigenic variability) & PF00823 & $5.60 \mathrm{E}-06$ & $1.00 \mathrm{E}+01$ \\
\hline${ }^{\mathrm{b}}$ Proteins of 100 residues with WXG (esx-related) & PF06013 & $7.10 \mathrm{E}-06$ & $7.90 \mathrm{E}+00$ \\
\hline b Phd YefM (toxin-antitoxin-related) & PF02604 & $7.70 \mathrm{E}-06$ & $9.00 \mathrm{E}+00$ \\
\hline Ponericin & PF07442 & 7.70E-06 & $8.70 \mathrm{E}+00$ \\
\hline b Plasmid stabilization system protein (toxin-antitoxin-related) & PF05016 & 9.90E-06 & $9.30 \mathrm{E}+00$ \\
\hline Threonine leader peptide & PF08254 & $1.10 \mathrm{E}-05$ & $8.90 \mathrm{E}+00$ \\
\hline Toxin 33 Waglerin family & PF08121 & $2.20 \mathrm{E}-05$ & $3.20 \mathrm{E}+00$ \\
\hline Phosphatidylethanolamine-binding protein & PF01161 & $2.20 \mathrm{E}-05$ & $7.30 \mathrm{E}+00$ \\
\hline b PemK-like protein (toxin-antitoxin-related) & PF02452 & $3.10 \mathrm{E}-05$ & $9.00 \mathrm{E}+00$ \\
\hline Erythronolide synthase docking & PF08990 & $5.60 \mathrm{E}-05$ & $7.30 \mathrm{E}+00$ \\
\hline${ }^{\mathrm{d}}$ Radical SAM superfamily & PF04055 & $5.80 \mathrm{E}-05$ & $3.90 \mathrm{E}+00$ \\
\hline d ThiS family & PF02597 & $6.60 \mathrm{E}-05$ & $5.60 \mathrm{E}+00$ \\
\hline b Pentapeptide repeats (8 copies) & PF01469 & $1.20 \mathrm{E}-04$ & $1.00 \mathrm{E}+01$ \\
\hline Rubredoxin & PF00301 & $1.30 \mathrm{E}-04$ & $3.80 \mathrm{E}+00$ \\
\hline d Pterin 4 alpha carbinolamine dehydratase & PF01329 & $1.50 \mathrm{E}-04$ & $8.80 \mathrm{E}+00$ \\
\hline Leucine rich repeat $\mathrm{N}$-terminal domain & PF01462 & $1.60 \mathrm{E}-04$ & $1.00 \mathrm{E}+01$ \\
\hline e Domain of unknown function (DUF1610) & PF07754 & $2.10 \mathrm{E}-04$ & $2.40 \mathrm{E}+00$ \\
\hline SEC-C motif & PF02810 & 2.30E-04 & $3.00 \mathrm{E}+00$ \\
\hline d MoaC family & PF01967 & 2.60E-04 & 7.10E+00 \\
\hline Berberine and berberine like & PF08031 & $2.70 \mathrm{E}-04$ & $9.30 \mathrm{E}+00$ \\
\hline Cytochrome B6-F complex subunit VI (PetL) & PF05115 & $2.80 \mathrm{E}-04$ & $9.40 \mathrm{E}+00$ \\
\hline Region found in RelA/SpoT proteins & PF04607 & $3.00 \mathrm{E}-04$ & $5.00 \mathrm{E}+00$ \\
\hline Quinolinate phosphoribosyl transferase, C-terminal domain & PF01729 & 3.30E-04 & 4.20E+00 \\
\hline Fumarate reductase subunit $C$ & PF02300 & 3.70E-04 & $1.00 \mathrm{E}+01$ \\
\hline LHC Antenna complex alpha/beta subunit & PF00556 & $5.00 \mathrm{E}-04$ & $3.20 \mathrm{E}+00$ \\
\hline RNPHF zinc finger & PF08080 & $5.10 \mathrm{E}-04$ & $6.50 \mathrm{E}+00$ \\
\hline Protein of unknown function (DUF1416) & PF07210 & $5.20 \mathrm{E}-04$ & $9.60 \mathrm{E}+00$ \\
\hline
\end{tabular}


Table 250 PFAM categories most expanded in the Mtb clade relative to the non-pathogenic, soil-dwelling Mycobacteria (Continued)

\begin{tabular}{llll}
\hline PsbJ & PF01788 & $5.40 \mathrm{E}-04$ & $3.70 \mathrm{E}+00$ \\
\hline Bacterial transferase hexapeptide (three repeats) & PF00132 & $5.50 \mathrm{E}-04$ & $3.00 \mathrm{E}+00$ \\
\hline $\mathrm{N}$ Chalcone and stilbene synthases, N-terminal domain & PF00195 & $6.60 \mathrm{E}-04$ & $8.40 \mathrm{E}+00$ \\
\hline${ }^{\mathrm{d}}$ MoaE protein & PF02391 & $8.00 \mathrm{E}-04$ & $7.80 \mathrm{E}+00$ \\
\hline${ }^{\mathrm{b}}$ Protein of unknown function (DUF1066) (esx) & PF06359 & $8.30 \mathrm{E}-04$ & $1.10 \mathrm{E}+01$ \\
\hline
\end{tabular}

${ }^{a}$ Bonferroni-corrected $\mathrm{p}$-value calculated from T-test

${ }^{\mathrm{b}}$ pathogenicity or survival within the host

' Lipid metabolism

${ }^{d}$ Pterin cofactor biosynthesis

e unknown function

Table 3 The 50 GO terms most expanded in the Mtb clade relative to the non-pathogenic, soil-dwelling Mycobacteria

\begin{tabular}{|c|c|c|c|}
\hline GO descriptor & GO term ID & p-value ${ }^{a}$ & inter-to-intra centroid difference \\
\hline 4-hydroxy-3-methylbut-2-en-1-yl diphosphate red. activity & GO_0051745 & $4.80 \mathrm{E}-08$ & $7.20 \mathrm{E}+00$ \\
\hline dTMP biosynthetic process & GO_0006231 & 7.30E-07 & $4.40 \mathrm{E}+00$ \\
\hline response to CAMP & GO_0051591 & $1.40 \mathrm{E}-06$ & $1.20 \mathrm{E}+01$ \\
\hline succinate dehydrogenase (ubiquinone) activity & GO_0008177 & $1.70 \mathrm{E}-06$ & $5.10 \mathrm{E}+00$ \\
\hline iron ion transport & GO_0006826 & 2.70E-06 & $4.70 \mathrm{E}+00$ \\
\hline magnesium ion binding & GO_0000287 & $2.80 \mathrm{E}-06$ & $1.70 \mathrm{E}+00$ \\
\hline${ }^{c}$ fatty-acyl-CoA synthase activity & GO_0004321 & $5.10 \mathrm{E}-06$ & $6.50 \mathrm{E}+00$ \\
\hline c acyltransferase activity & GO_0008415 & $7.60 \mathrm{E}-06$ & $3.60 \mathrm{E}+00$ \\
\hline transferase activity, transferring alkyl or aryl (other than methyl) groups & GO_0016765 & 1.30E-05 & $2.60 \mathrm{E}+00$ \\
\hline${ }^{c}$ tricarboxylic acid cycle & GO_0006099 & 1.30E-05 & $3.40 \mathrm{E}+00$ \\
\hline d Mo-molybdopterin cofactor biosynthetic process & GO_0006777 & $1.40 \mathrm{E}-05$ & $6.30 \mathrm{E}+00$ \\
\hline integral to membrane & GO_0016021 & $2.00 \mathrm{E}-05$ & $2.00 \mathrm{E}+00$ \\
\hline acid phosphatase activity & GO_0003993 & $2.50 \mathrm{E}-05$ & $3.20 \mathrm{E}+00$ \\
\hline phosphatase activity & GO_0016791 & $3.20 \mathrm{E}-05$ & $4.10 \mathrm{E}+00$ \\
\hline erythronolide synthase activity & GO_0047879 & 4.20E-05 & $8.20 \mathrm{E}+00$ \\
\hline d-alpha-hydroxytetrahydrobiopterin dehydratase activity & GO_0008124 & $6.80 \mathrm{E}-05$ & $6.20 \mathrm{E}+00$ \\
\hline${ }^{c}$ lipid metabolic process & GO_0006629 & $6.80 \mathrm{E}-05$ & $4.70 \mathrm{E}+00$ \\
\hline bacteriochlorophyll biosynthetic process & GO_0030494 & 7.00E-05 & $1.30 \mathrm{E}+00$ \\
\hline plasma membrane & GO_0005886 & 7.10E-05 & $2.70 \mathrm{E}+00$ \\
\hline d tetrahydrobiopterin biosynthetic process & GO_0006729 & 1.10E-04 & $8.80 \mathrm{E}+00$ \\
\hline${ }^{c}$ lipid biosynthetic process & GO_0008610 & $1.20 \mathrm{E}-04$ & $3.50 \mathrm{E}+00$ \\
\hline phosphatidylcholine metabolic process & GO_0046470 & $1.60 \mathrm{E}-04$ & $9.50 \mathrm{E}+00$ \\
\hline ¿ geranyltranstransferase activity & GO_0004337 & $1.60 \mathrm{E}-04$ & $6.80 \mathrm{E}+00$ \\
\hline cytoplasm & GO_0005737 & 1.90E-04 & $1.40 \mathrm{E}+00$ \\
\hline protein transport & GO_0015031 & $1.90 \mathrm{E}-04$ & $1.70 \mathrm{E}+00$ \\
\hline guanosine tetraphosphate metabolic process & GO_0015969 & $2.20 \mathrm{E}-04$ & $5.00 \mathrm{E}+00$ \\
\hline glyoxylate cycle & GO_0006097 & 2.20E-04 & $4.30 \mathrm{E}+00$ \\
\hline phosphoglycolate phosphatase activity & GO_0008967 & $2.80 \mathrm{E}-04$ & $4.30 \mathrm{E}+00$ \\
\hline terpenoid biosynthetic process & GO_0016114 & 3.90E-04 & $2.80 \mathrm{E}+00$ \\
\hline sulfur metabolic process & GO_0006790 & 4.10E-04 & $5.30 \mathrm{E}+00$ \\
\hline 4 iron, 4 sulfur cluster binding & GO_0051539 & 5.00E-04 & $2.90 \mathrm{E}+00$ \\
\hline succinate dehydrogenase activity & GO_0000104 & 5.70E-04 & $4.60 \mathrm{E}+00$ \\
\hline${ }^{\mathrm{b}}$ mycocerosate synthase activity & GO_0050111 & $5.80 \mathrm{E}-04$ & $4.10 \mathrm{E}+00$ \\
\hline${ }^{c}$ phospholipid biosynthetic process & GO_0008654 & $6.10 \mathrm{E}-04$ & $2.30 \mathrm{E}+00$ \\
\hline nucleoside metabolic process & GO_0009116 & $6.30 \mathrm{E}-04$ & $3.60 \mathrm{E}+00$ \\
\hline
\end{tabular}


Table 3 The 50 GO terms most expanded in the Mtb clade relative to the non-pathogenic, soil-dwelling Mycobacteria (Continued)

\begin{tabular}{|c|c|c|c|}
\hline c phosphopantetheine binding & GO_0031177 & $8.20 \mathrm{E}-04$ & $3.00 \mathrm{E}+00$ \\
\hline adenylate cyclase activity & GO_0004016 & 8.30E-04 & $5.50 \mathrm{E}+00$ \\
\hline D-arabinono-1,4-lactone oxidase activity & GO_0003885 & 9.70E-04 & $8.40 \mathrm{E}+00$ \\
\hline anaerobic respiration & GO_0009061 & 9.90E-04 & $1.10 \mathrm{E}+01$ \\
\hline nodulation & GO_0009877 & 1.10E-03 & $7.10 \mathrm{E}+00$ \\
\hline${ }^{{ }^{c} \text { prenyltransferase activity }}$ & GO_0004659 & 1.10E-03 & $4.20 E+00$ \\
\hline${ }^{c}$ lysophospholipase activity & GO_0004622 & 1.30E-03 & $8.50 \mathrm{E}+00$ \\
\hline c acetyl-CoA carboxylase activity & GO_0003989 & 1.30E-03 & $2.40 \mathrm{E}+00$ \\
\hline histidinol-phosphatase activity & GO_0004401 & 2.10E-03 & $6.50 \mathrm{E}+00$ \\
\hline pyridine nucleotide biosynthetic process & GO_0019363 & 2.30E-03 & $5.00 \mathrm{E}+00$ \\
\hline NAD biosynthetic process & GO_0009435 & 3.30E-03 & $1.30 \mathrm{E}+00$ \\
\hline lactate fermentation to propionate and acetate & GO_0019652 & $3.40 \mathrm{E}-03$ & $3.40 \mathrm{E}+00$ \\
\hline alkylglycerone-phosphate synthase activity & GO_0008609 & $3.40 \mathrm{E}-03$ & $7.10 \mathrm{E}+00$ \\
\hline${ }^{\mathrm{b}}$ cyclopropane-fatty-acyl-phospholipid synthase activity & GO_0008825 & 4.00E-03 & $5.90 \mathrm{E}+00$ \\
\hline methylcrotonoyl-CoA carboxylase activity & GO_0004485 & 4.40E-03 & $3.00 \mathrm{E}+00$ \\
\hline
\end{tabular}

${ }^{a}$ Bonferroni-corrected $p$-value calculated from T-test

${ }^{\mathrm{b}}$ pathogenicity or survival within the host

c Lipid metabolism

${ }^{d}$ Cofactor biosynthesis

e unknown function

Table 4 The 50 PFAM categories most expanded in the Mycobacteria relative to the non- Mycobacteria

\begin{tabular}{|c|c|c|c|}
\hline PFAM descriptor & PFAM ID & p-value ${ }^{a}$ & inter-to-intra centroid difference \\
\hline e Protein of unknown function (DUF2599) & PF10783 & 1.50E-10 & $8.80 \mathrm{E}+00$ \\
\hline${ }^{c}$ Cutinase & PF01083 & 1.60E-10 & $1.50 \mathrm{E}+01$ \\
\hline e Uncharacterized protein conserved in bacteria (DUF2236) & PF09995 & $2.20 \mathrm{E}-10$ & $1.60 \mathrm{E}+01$ \\
\hline 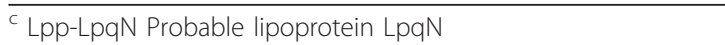 & PF10738 & $4.70 \mathrm{E}-10$ & $1.30 \mathrm{E}+01$ \\
\hline e Domain of unknown function (DUF385) & PF04075 & 5.70E-10 & $1.30 \mathrm{E}+01$ \\
\hline${ }^{\mathrm{b}}$ Domain of unk function DUF140 (yrbE genes in mce operons) & PF02405 & 1.60E-09 & $1.40 \mathrm{E}+01$ \\
\hline Retinal pigment epithelial membrane protein & PF03055 & 8.50E-09 & $1.40 \mathrm{E}+01$ \\
\hline e Domain of unknown function (DUF427) & PF04248 & 1.40E-08 & $1.60 \mathrm{E}+01$ \\
\hline ABC transporter transmembrane region 2 PF06472 & PF06472 & 1.80E-08 & $1.10 \mathrm{E}+01$ \\
\hline${ }_{\mathrm{b}}$ Peroxidase (katG-isoniazid resistance) & PF00141 & 4.10E-08 & $1.20 \mathrm{E}+01$ \\
\hline${ }_{\mathrm{b}}$ mce related protein & PF02470 & 1.30E-07 & $1.30 \mathrm{E}+01$ \\
\hline N O-methyltransferase $\mathrm{N}$-terminus & PF02409 & 1.70E-07 & $1.70 \mathrm{E}+01$ \\
\hline Activator of Hsp90 ATPase homolog 1-like protein & PF08327 & $2.40 \mathrm{E}-07$ & $1.10 \mathrm{E}+01$ \\
\hline Coronavirus nonstructural protein NS1 & PF06145 & $3.00 \mathrm{E}-07$ & $1.20 \mathrm{E}+01$ \\
\hline e Predicted integral membrane protein (DUF2189) & PF09955 & $3.10 \mathrm{E}-07$ & $1.40 \mathrm{E}+01$ \\
\hline e Uncharacterized protein family (UPF0089) & PF03007 & $3.80 \mathrm{E}-07$ & $1.50 \mathrm{E}+01$ \\
\hline${ }^{\mathrm{b}}$ Acetyltransf $2 \mathrm{~N}$-acetyltransferase (inactivates isoniazid) & PF00797 & 3.90E-07 & $1.70 \mathrm{E}+01$ \\
\hline${ }^{\mathrm{e}}$ Domain of unknown function (DUF1957) & PF09210 & $5.50 \mathrm{E}-07$ & $7.90 \mathrm{E}+00$ \\
\hline KRAB box & PF01352 & 7.00E-07 & $1.70 \mathrm{E}+01$ \\
\hline Prokaryotic acetaldehyde dehydrogenase, dimerisation & PF09290 & 8.10E-07 & $9.00 \mathrm{E}+00$ \\
\hline DmpG-like communication domain & PF07836 & 9.50E-07 & $1.10 \mathrm{E}+01$ \\
\hline Nuclear transport factor 2 (NTF2) domain & PF02136 & $1.00 \mathrm{E}-06$ & $1.30 \mathrm{E}+01$ \\
\hline Wyosine base formation & PF08608 & 1.10E-06 & $1.40 \mathrm{E}+01$ \\
\hline AIG2-like family & PF06094 & 1.30E-06 & $1.80 \mathrm{E}+01$ \\
\hline e Protein of unknown function (DUF867) & PF05908 & $1.30 \mathrm{E}-06$ & $1.50 \mathrm{E}+01$ \\
\hline
\end{tabular}


Table 4 The 50 PFAM categories most expanded in the Mycobacteria relative to the non- Mycobacteria (Continued)

\begin{tabular}{|c|c|c|c|}
\hline Phage-related minor tail protein & PF10145 & $2.10 \mathrm{E}-06$ & $1.20 \mathrm{E}+01$ \\
\hline${ }^{\mathrm{C}}$ Fatty acid desaturase & PF03405 & 2.30E-06 & $1.00 \mathrm{E}+01$ \\
\hline PaaX-like protein & PF07848 & $2.80 \mathrm{E}-06$ & $1.50 \mathrm{E}+01$ \\
\hline Adenylate and Guanylate cyclase catalytic domain & PF00211 & 3.70E-06 & $1.10 \mathrm{E}+01$ \\
\hline Fibronectin-attachment protein (FAP) & PF07174 & $3.80 \mathrm{E}-06$ & 1.30E+01 \\
\hline Leucine Rich Repeat & PF07723 & 5.50E-06 & 1.10E+01 \\
\hline 2-nitropropane dioxygenase & PF03060 & $5.70 \mathrm{E}-06$ & $1.40 \mathrm{E}+01$ \\
\hline${ }^{\mathrm{c}}$ Fatty acid desaturase & PF00487 & 7.90E-06 & $1.30 \mathrm{E}+01$ \\
\hline e Protein of unknown function (DUF732) & PF05305 & $9.10 \mathrm{E}-06$ & $1.50 \mathrm{E}+01$ \\
\hline c Enoyl-CoA hydratase/isomerase family & PF00378 & $9.70 \mathrm{E}-06$ & $1.10 \mathrm{E}+01$ \\
\hline arg-2/CPA1 leader peptide & PF08252 & $1.00 \mathrm{E}-05$ & $1.40 \mathrm{E}+01$ \\
\hline c alpha/beta hydrolase fold (lipases) & PF07859 & 1.10E-05 & $1.50 \mathrm{E}+01$ \\
\hline Cytochrome P450 & PF00067 & $1.40 \mathrm{E}-05$ & $1.20 \mathrm{E}+01$ \\
\hline c Cyclopropane-fatty-acyl-phospholipid synthase PF02353 & PF02353 & $1.60 \mathrm{E}-05$ & $1.20 \mathrm{E}+01$ \\
\hline Isoprenylcysteine carboxyl methyltransferase (ICMT) family & PF04140 & $1.90 \mathrm{E}-05$ & $1.50 \mathrm{E}+01$ \\
\hline Hydratase/decarboxylase & PF01689 & $2.50 \mathrm{E}-05$ & $6.60 \mathrm{E}+00$ \\
\hline PsbJ & PF01788 & $3.00 \mathrm{E}-05$ & $9.40 E+00$ \\
\hline Linocin M18 bacteriocin protein & PF04454 & 3.40E-05 & $1.60 \mathrm{E}+01$ \\
\hline Extensin-like protein repeat & PF02095 & 4.00E-05 & $1.50 \mathrm{E}+01$ \\
\hline $5 \mathrm{HT}$ transporter Serotonin $(5-\mathrm{HT})$ neurotransmitter transporter, $\mathrm{N}$-terminus & PF03491 & 4.00E-05 & $9.50 \mathrm{E}+00$ \\
\hline e Protein of unknown function (DUF571) & PF04600 & $4.20 \mathrm{E}-05$ & $7.70 \mathrm{E}+00$ \\
\hline Tryptophyllin-3 skin active peptide & PF08248 & 4.90E-05 & $1.50 \mathrm{E}+01$ \\
\hline AMP-binding enzyme & PF00501 & 8.10E-05 & $9.20 \mathrm{E}+00$ \\
\hline e Bacterial protein of unknown function (DUF853) & PF05872 & 9.90E-05 & $1.30 \mathrm{E}+01$ \\
\hline${ }^{c}$ Acyl-ACP thioesterase & PF01643 & 1.10E-04 & 1.10E+01 \\
\hline
\end{tabular}

${ }^{\mathrm{a} B o n f e r r o n i-c o r r e c t e d ~} \mathrm{p}$-value calculated from T-test

${ }^{b}$ pathogenicity or survival within the host

c Lipid metabolism

${ }^{d}$ Cofactor biosynthesis

e unknown function

Table 5 The 50 GO terms most expanded in the Mycobacteria relative to the non- Mycobacteria

\begin{tabular}{|c|c|c|c|}
\hline GO term descriptor & $\begin{array}{l}\text { GO term } \\
\text { ID }\end{array}$ & $\begin{array}{l}\mathrm{p}- \\
\text { value }^{\mathrm{a}}\end{array}$ & $\begin{array}{l}\text { inter-to-intra-centroid } \\
\text { difference }\end{array}$ \\
\hline c sterol biosynthetic process & GO:0016126 & 1.00E-10 & $1.80 \mathrm{E}+01$ \\
\hline${ }_{\mathrm{b}}^{\mathrm{b}}$ regulation of apoptosis & GO:0042981 & 1.10E-10 & $1.90 \mathrm{E}+01$ \\
\hline c 3alpha,7alpha,12alpha-trihydroxy-5beta- cholest-24-enoyl-CoA hydratase activity & GO:0033989 & $1.40 \mathrm{E}-10$ & $1.70 \mathrm{E}+01$ \\
\hline c linalool 8-monooxygenase activity & GO:0050056 & $1.50 \mathrm{E}-10$ & $1.70 \mathrm{E}+01$ \\
\hline c sterol 14-demethylase activity & GO:0008398 & 5.10E-09 & $1.60 \mathrm{E}+01$ \\
\hline ' cutinase activity & GO:0050525 & 5.80E-09 & $1.60 \mathrm{E}+01$ \\
\hline oxidoreductase activity, acting on NADH or NADPH, nitrogenous group as acceptor & GO:0016657 & 1.80E-08 & $1.40 \mathrm{E}+01$ \\
\hline c diacylglycerol O-acyltransferase activity & GO:0004144 & $2.10 \mathrm{E}-08$ & $1.70 \mathrm{E}+01$ \\
\hline ligase activity, forming carbon-carbon bonds & GO:0016885 & $6.10 \mathrm{E}-08$ & $1.40 \mathrm{E}+01$ \\
\hline indolylacetylinositol arabinosyltransferase activity & GO:0050409 & 7.90E-08 & $1.20 \mathrm{E}+01$ \\
\hline c 4-hydroxy-2-oxovalerate aldolase activity & GO:0008701 & $1.00 \mathrm{E}-07$ & $1.10 \mathrm{E}+01$ \\
\hline arylamine $\mathrm{N}$-acetyltransferase activity & GO:0004060 & $2.80 \mathrm{E}-07$ & $1.70 \mathrm{E}+01$ \\
\hline${ }^{c}$ lipid transport & GO:0006869 & $5.00 \mathrm{E}-07$ & $1.70 \mathrm{E}+01$ \\
\hline${ }^{{ }^{c} \text { lipid biosynthetic process }}$ & GO:0008610 & $5.00 \mathrm{E}-07$ & $8.50 \mathrm{E}+00$ \\
\hline
\end{tabular}


Table 5 The $\mathbf{5 0}$ GO terms most expanded in the Mycobacteria relative to the non- Mycobacteria (Continued)

\begin{tabular}{|c|c|c|c|}
\hline biphenyl-2,3-diol 1,2-dioxygenase activity & GO:0018583 & $1.40 \mathrm{E}-06$ & $9.50 \mathrm{E}+00$ \\
\hline cis-stilbene-oxide hydrolase activity & GO:0033961 & $1.50 \mathrm{E}-06$ & $1.20 \mathrm{E}+01$ \\
\hline c acyl-[acyl-carrier-protein] desaturase activity & GO:0045300 & $1.70 \mathrm{E}-06$ & $1.00 \mathrm{E}+01$ \\
\hline 5-carboxymethyl-2-hydroxymuconic-semialdehyde dehydrog activity & GO:0018480 & $2.00 \mathrm{E}-06$ & $1.20 \mathrm{E}+01$ \\
\hline $\begin{array}{c}\text { fatty-acyl-CoA synthase activity } \\
\text {. }\end{array}$ & GO:0004321 & $2.10 \mathrm{E}-06$ & $1.20 \mathrm{E}+01$ \\
\hline $\begin{array}{c}\text { steroid biosynthetic process } \\
\end{array}$ & GO:0006694 & $2.30 \mathrm{E}-06$ & $1.20 \mathrm{E}+01$ \\
\hline $\begin{array}{c}\text { c propanoyl-CoA C-acyltransferase activity } \\
\end{array}$ & GO:0033814 & 2.50E-06 & $1.20 \mathrm{E}+01$ \\
\hline extracellular matrix binding & GO:0050840 & 2.70E-06 & $1.30 \mathrm{E}+01$ \\
\hline lipid glycosylation & GO:0030259 & $6.70 \mathrm{E}-06$ & $5.60 \mathrm{E}+00$ \\
\hline $\begin{array}{l}\text { d coenzyme F420-dependent N5, N10-methenyltetrahydromethanopterinreductase } \\
\text { activity }\end{array}$ & GO:0018537 & $6.90 \mathrm{E}-06$ & $1.20 \mathrm{E}+01$ \\
\hline C-terminal protein amino acid methylation & GO:0006481 & 1.10E-05 & $1.10 \mathrm{E}+01$ \\
\hline metabolic process & GO:0008152 & $1.30 \mathrm{E}-05$ & $4.60 \mathrm{E}+00$ \\
\hline 4-oxalocrotonate decarboxylase activity & GO:0047437 & 1.70E-05 & $1.10 \mathrm{E}+01$ \\
\hline oxidoreductase activity & GO:0016491 & $1.80 \mathrm{E}-05$ & $5.20 \mathrm{E}+00$ \\
\hline oxidation reduction & GO:0055114 & $1.90 \mathrm{E}-05$ & $4.80 \mathrm{E}+00$ \\
\hline defense response to bacterium & GO:0042742 & $2.40 \mathrm{E}-05$ & $1.60 \mathrm{E}+01$ \\
\hline b cyclopropane-fatty-acyl-phospholipid synthase activity & GO:0008825 & $2.90 \mathrm{E}-05$ & $9.80 \mathrm{E}+00$ \\
\hline c 3-hydroxy-2-methylbutyryl-CoA dehyd. activity & GO:0047015 & $3.40 \mathrm{E}-05$ & $1.10 \mathrm{E}+01$ \\
\hline nutrient reservoir activity & GO:0045735 & $3.40 \mathrm{E}-05$ & $9.30 \mathrm{E}+00$ \\
\hline structural constituent of cell wall & GO:0005199 & $3.60 \mathrm{E}-05$ & $7.90 \mathrm{E}+00$ \\
\hline 2-nitropropane dioxygenase activity & GO:0018580 & 4.10E-05 & $1.40 \mathrm{E}+01$ \\
\hline adenylate cyclase activity & GO:0004016 & 6.00E-05 & $9.50 \mathrm{E}+00$ \\
\hline${ }^{\mathrm{b}}$ beta-lactam antibiotic catabolic process & GO:0030655 & $6.70 \mathrm{E}-05$ & $1.40 \mathrm{E}+01$ \\
\hline DNA primase activity & GO:0003896 & $8.40 \mathrm{E}-05$ & $1.10 \mathrm{E}+01$ \\
\hline cyclic nucleotide biosynthetic process & GO:0009190 & $8.50 \mathrm{E}-05$ & $9.80 \mathrm{E}+00$ \\
\hline iron ion transport & GO:0006826 & 8.70E-05 & $1.20 \mathrm{E}+01$ \\
\hline di-, tri-valent inorganic cation transmembrane transporter activity & GO:0015082 & $9.00 \mathrm{E}-05$ & $6.80 \mathrm{E}+00$ \\
\hline phosphorus-oxygen lyase activity & GO:0016849 & $1.60 \mathrm{E}-04$ & $9.50 \mathrm{E}+00$ \\
\hline limonene-1,2-epoxide hydrolase activity & GO:0018744 & 1.60E-04 & $7.80 \mathrm{E}+00$ \\
\hline${ }^{c}$ fatty acid metabolic process & GO:0006631 & 1.70E-04 & $8.40 \mathrm{E}+00$ \\
\hline sirohydrochlorin cobaltochelatase activity & GO:0016852 & $1.80 \mathrm{E}-04$ & $1.50 \mathrm{E}+01$ \\
\hline intracellular signaling cascade & GO:0007242 & $2.00 \mathrm{E}-04$ & $8.80 \mathrm{E}+00$ \\
\hline c enoyl-CoA hydratase activity & GO:0004300 & $2.30 \mathrm{E}-04$ & $1.30 \mathrm{E}+01$ \\
\hline di-, tri-valent inorganic cation transport & GO:0015674 & $2.40 \mathrm{E}-04$ & $6.20 \mathrm{E}+00$ \\
\hline $\mathrm{C}_{\text {acyl-CoA dehydrogenase activity }}$ & GO:0003995 & $2.60 \mathrm{E}-04$ & $9.10 \mathrm{E}+00$ \\
\hline catechol O-methyltransferase activity & GO:0016206 & $3.20 \mathrm{E}-04$ & $1.50 \mathrm{E}+01$ \\
\hline
\end{tabular}

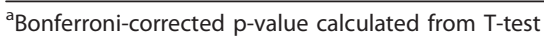

${ }^{b}$ pathogenicity or survival within the host

c Lipid metabolism

${ }^{\mathrm{d}}$ Cofactor biosynthesis

e unknown function

long term survival of the pathogen metabolizing host lipids encountered during infection.

\section{Coordinated evolution of lipid metabolism genes and the regulator KstR}

KstR is a transcription factor known to be involved in lipid and cholesterol degradation [36,37]. It has been recently shown that $M t b$ uses cholesterol as a carbon source within the host [32]. Strikingly, KstR exhibits an evolutionary history that parallels the expansion of lipid metabolism genes in the Mycobacteria, and displays a singular conservation in its regulatory binding sites.

KstR appears to have evolved at the last common ancestor of the Mycobacteria and Rhodococcus. In all 


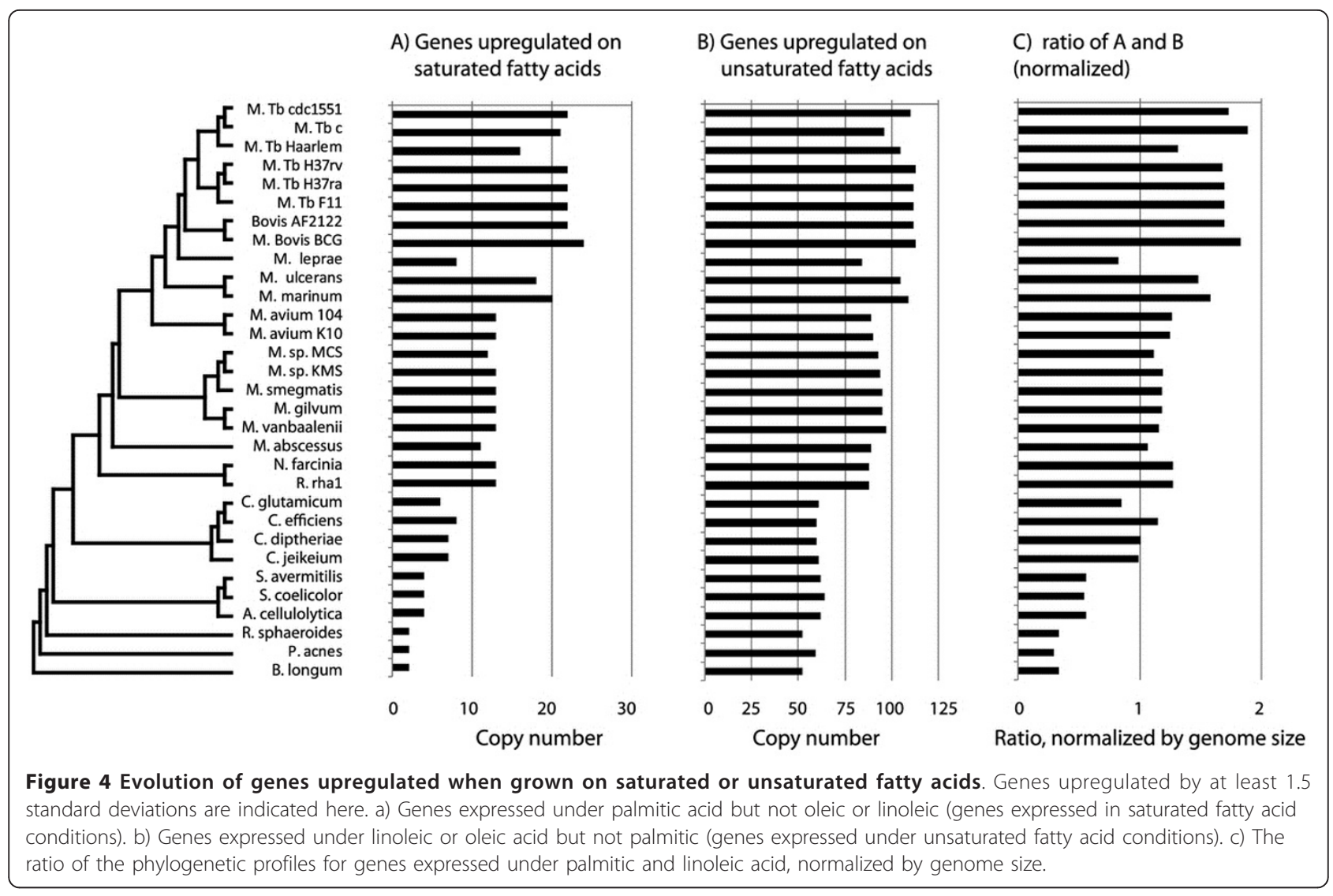

Mycobacteria analyzed (except M. leprae), Rhodococcus, and Nocardia there is one highly conserved ortholog of the KstR gene. However, in organisms more distantly related to $M t b$, the $K s t R$ gene is not present in a single copy. Rather, 2-3 paralogs of KstR are present in these more distantly related organisms, as well as the environmental Mycobacteria, including $M$. ulcerans, M. avium 104, M. sp. MCS, M. sp. KMS, and M. vanbaalenii (Additional file 2: Figure S1). Remarkably, these paralogs of KstR are all absent in the pathogenic Mycobacteria. Thus, coincident with the expansion in lipid metabolism genes described above, the KstR gene appears to have emerged through gene duplication within the existing gene family of tetR-like transcriptional regulators at the last common ancestor of Mycobacteria and Rhodococcus. All other members of this gene family were subsequently lost in the $M t b$ complex, while the KstR protein was maintained and underwent limited sequence divergence.

There is another homolog to KstR found in Mtb H37Rv $(R v 3557 c)$ that has previously been reported to also be involved in cholesterol metabolism, named KstR2 [38]. However, KstR is much more similar to the other members of the Mycobacterial tetR family discussed above than it is to KstR2. KstR2 is categorized into a separate orthogroup (orthogroup 32655) and is more distantly related to KstR.

The high sequence conservation of the KstR transcription factor is mirrored in the conservation of KstR binding sites across numerous promoters. KstR binding sites are known to be highly conserved across the Mycobacteria, out to Rhodococcus and Nocardia [36]. These sites are conserved in both sequence and position within their respective promoters. In our analysis, both in searches using known transcription factor binding motifs, as well as in our de novo motif searches, a subset of KstR binding sites are the most conserved transcription factor motifs observed. They are also among the most conserved of any noncoding sequence we identified. The conservation of the KstR gene and binding sites, the emergence of KstR at the ancestor of Rhodococcus and the Mycobacteria, and the loss of KstR paralogs within the pathogenic Mycobacteria, suggests that this transcription factor and its evolving regulon have played an important role in the expansion of lipid metabolism and its adaptation to pathogenicity in $M t b$.

\section{Positive selection of DNA repair genes}

$M t b$, as well as non-tuberculous Mycobacteria, differ from other bacteria in several key respects of DNA repair 
[39-42]. Within the host, $M t b$ must combat damage to its DNA from macrophage-generated reactive oxygen and nitrogen intermediates. The mechanisms by which this is accomplished are not fully understood $[43,44]$. Although genes implicated in DNA repair have not expanded in the $M t b$ lineage, we note that the set of genes showing positive selection on the $M t b$ lineage in our $\mathrm{d}_{\mathrm{N}} / \mathrm{d}_{\mathrm{S}}$ analysis is enriched for genes involved in the COG category for DNA replication, recombination, and repair (Additional file 1: Table S2). Several of the genes in this set with highest $d_{N} / d_{S}$ values are known DNA repair genes (including $\operatorname{rec} A, \operatorname{rec} B$, and $d n a E 2$ ), and several additional genes are helicases (dnaB, helZ, and gyrB).

Interestingly, we observe that $\operatorname{rec} A$ has the highest $\mathrm{d}_{\mathrm{N}} /$ $\mathrm{d}_{\mathrm{S}}$ score of all the genes in $M t b$ on the branch leading to the $M t b$ complex, and $\operatorname{rec} B$ also has a very high score. Mycobacteria lack a mutSL-based mismatch repair (MMR) system [42], and it is believed that $\operatorname{rec} A$ may be involved in compensating pathways. dnaE2 (DNA polymerase III) also has one of the highest $\mathrm{d}_{\mathrm{N}} / \mathrm{d}_{\mathrm{S}}$ values on the branch leading to $M t b$, and both dnaE1 (DNA polymerase III) and dnaE2 show evidence of selection on the branch leading to the pathogenic Mycobacteria. In $M t b$, damage-induced base-substitution mutagenesis is dependent on $d n a E 2$. Loss of $d n a E 2$ activity renders $M t b$ hypersensitive to DNA damage, eliminates induced mutagenesis, attenuates virulence, and reduces the frequency of drug resistance in vivo $[39,45]$. dnaE1 provides essential, high-fidelity replicative polymerase function [39], and is expressed in response to DNA damage, along with $d n a E 2$ and $\operatorname{rec} A[39,45]$.

We also observe positive selection for $\operatorname{din} X$ (DNA polymerase IV) on the branch leading to the pathogenic Mycobacteria (branch-site model) in our $\mathrm{d}_{\mathrm{N}} / \mathrm{d}_{\mathrm{S}}$ analysis (see Supplementary Information website). Most organisms use specialized DNA polymerases that are able to catalyze translesion synthesis (TLS) across sites of damage, including the $\operatorname{din} B$ group of $Y$ family polymerases. There are two $\operatorname{din} B$-family polymerases in $M t b(\operatorname{din} X$ and $\operatorname{din} P)$. Unlike in other bacteria, $\operatorname{din} X$ and $\operatorname{din} P$ expression are not dependent on $r e c A$, the SOS response, or the presence of DNA damage, and could therefore serve a novel yet uncharacterized role in $M t b$ [46-49].

\section{Expansion of pterin cofactors}

Genes involved in the first steps of pterin cofactor (a component of the molybdenum cofactor) biosynthesis are known to be expanded in the $M t b$ complex [50]. Molybdenum cofactor-requiring enzymes (such as xanthine oxidase and aldehyde oxidase) could have physiological functions in the metabolism of reactive oxygen species during stress response [51]. Molybdenum cofactor is an efficient catalyst in oxygen-transfer reactions, can be used in anaerobic respiration, and can catalyze redox reactions in carbon, nitrogen, and sulfur metabolism. Recently, genes related to molybdenum cofactor protein synthesis have been shown to be upregulated under conditions of stress in $M t b$ [52]. Molybdenum cofactor biosynthesis has been previously linked to pathogenesis. The regulator of the moa1 locus, MoaR1, was identified as having a SNP in M. bovis BCG, but not in virulent $M$. bovis or $M t b$ [53]. In addition, moa3 is present with varying frequency in the RD1 region, which is absent in $M$. bovis $B C G$, of pathogenic strains [54].

In agreement with previous observations of expansions of molybdopterin biosynthesis genes, we observe five protein domains related to pterin cofactor biosynthesis among the top protein domains expanded in the $M t b$ complex compared to the non-pathogenic Mycobacteria (Table 2, -"d"). Among the top GO terms expanded in the $M t b$ clade relative to the soil dwellers (Table 3), there are also several groups involved in pterin and molybdopterin biosynthesis. Some of these gene copies (the moa1 locus) are believed to have been acquired by lateral gene transfer on the branch leading to the $M t b$ complex $[10,50]$.

We also observe evidence for selection on molybdenumrelated genes in our $d_{N} / d_{S}$ data. On the branch leading to the pathogenic Mycobacteria, several orthogroups with high log likelihood scores when testing for selection are related to molybdenum (see Supplementary Information website). The orthogroup containing BisC (biotin sulfoxide reductase, a molybdoenzyme), as well as the orthogroup containing ModA (an ABC-family molybdate transporter), are among those with the highest $d_{N} / d_{S}$ values on the branch leading to the pathogens. MoaB2 is one of the highest-scoring genes on all three branches tested.

\section{Expansions of genes of unknown function in Mtb clade}

There are also many categories of unknown function that are greatly expanded in the $M t b$ clade relative to the nonpathogenic Mycobacteria (Tables 2 and 3, red). For example, $R v 0918$ (in the Pfam group of unknown function PF08681) was found in a genetic screen that facilitates isolation of mutants defective in arresting the maturation of phagosomes [55], helping $M t b$ to survive within host cells. PF07161 contains four lipoproteins (LprF, LprG, LprA, LppX). $L p r G$ and $L p p X$ were found to be in vivo essential genes by TraSH analysis [56].

\section{Detection of conserved noncoding sequences}

Sequence conservation - or phylogenetic footprinting provides a powerful approach for identifying potential functional noncoding sequences, and has been used in a variety of eukaryotic and prokaryotic organisms to identify protein coding genes, noncoding RNAs, and regulatory elements $[57,58]$. For optimal power, the organisms being analyzed must be sufficiently distant such that non-functional elements have diverged, but not so distant such that 
functional elements have evolved or re-arranged. Organisms within the $M t b$ complex are all highly similar at the sequence level, and thus by themselves do not allow for effective phylogenetic footprinting. By leveraging the evolutionary similarity of the most distantly related Mycobacteria and Actinomycetes, we gained additional power to allow us to detect functional sequences under purifying selection, albeit only those shared by at least a majority of Mycobacteria. We used this approach to predict two classes of conserved noncoding sequences: small noncoding RNAs and transcription factor binding motifs.

\section{Novel putative conserved small noncoding RNAs in Mycobacteria}

Small noncoding RNAs (sRNAs) have been shown to play a role in regulating gene expression in numerous bacterial species [59], including Streptococcus [60,61]. Yet only recently were sRNAs reported in Mycobacteria [60,62]. Using a combination of direct isolation of small RNAs, and validation by Northern blotting and 5' and 3' RACE transcript mapping, Arnvig and Young [62] first described nine sRNAs in $M t b$. Subsequently, DiChiara et al. [63] describe 34 small RNAs in $M$. bovis BCG, of which many were conserved in both $M t b$ and $M$. smegmatis.

To build on these results, we used a combination of comparative genomics, RNA-seq, and experimental validation by Northern blotting to identify additional sRNAs conserved among the Mycobacteria (Methods). Our computational results provide evidence for 50 conserved small RNAs in $M t b$ that have not been previously reported. It is likely that additional conserved regions are expressed under other diverse conditions. Figure 5a shows the expression and conservation map for one of our predicted RNAs in the GenomeView Browser [64]. Table 6 shows a listing of the top 12 candidate RNAs. To verify a subset of these candidate small RNAs, we used Northern blot analysis on four of the top predicted regions (Methods). The results (Figure $5 \mathrm{~b}$ ) show signals corresponding to small RNAs from each of four candidates (Table 6, labeled 1, 2, 3 , and 9). All transcripts were near the expected size, or slightly larger. Full-length gels are provided in Additional file 3: Figure S2. Consistent with previous work, the majority of small RNAs were seen as more than one size transcript [62]. This suggests that small RNAs might be generated by processing of larger transcripts. In the RNAseq data, there are longer "tails" extending outside of the main peak that corresponds to the RNA prediction-different length RNAs could be responsible for the additional bands of higher mass.

\section{Conserved cis-regulatory motifs in Mycobacteria}

Few transcription factor binding motifs have been identified in $M t b$. Transcription factors for which binding motifs have been identified include KstR [36], DosR [67], IdeR
[68], ZurB [69], Crp [70], CsoR [71], FurA [72], MprAB [73], and Acr [74]. Because of the limited knowledge of transcriptional regulation in $M t b$, we searched for additional motifs computationally. We combined comparative sequence analysis with microarray data to identify a large number of motifs conserved in Mycobacteria.

We clustered microarray data contained in the TB database [75] and searched for upstream regulatory motifs shared in the upstream regions of the resulting clusters using AlignACE (Methods). Because of significant noise in the results, we used a set of stringent filters, including a requirement that candidate motifs be highly conserved. 37 motif instances passed our stringent filters (Table 7, Methods). 14 of the top 37 (38\%) motif instances correspond to cases of known $M t b$ motifs (several known $M t b$ motifs were found more than once, in different clusters, or in clusters with different size parameters). In contrast, none of the top motifs showed similarity only to known E. coli or Corynebacteria motifs. Within these top motifs, we were able to identify four of the nine known $M t b$ motifs (DosR, IdeR, KstR, and ZurB).

As described above, the KstR motif shows a much stronger signal, in terms of both conservation and information content, than any of the other motifs (top of the ranked conservation list, Table 7). Based on the distribution of highly conserved predicted motif instances for KstR across the genome, we predict a more general role for KstR in lipid metabolism. We see KstR motif instances near many other lipid genes not related to cholesterol degradation, in support of the view that KstR is a more general lipid regulator controlling a large regulon [36].

One of the most interesting new motif candidates that shows up in our analysis is a conserved palindromic motif, consisting of a highly conserved TAC... GTA separated by $6 \mathrm{bp}$ of less well conserved sequence (marked with an $\mathrm{X}$ in Table 7) that is found in clusters of 2-3 closely spaced sites upstream of several genes related to fatty acid metabolism (Figure 6). There is a cluster of 3 evenly spaced sites upstream of $R v 3229 c$ (linoeyl-coA desaturase), a cluster of 2 sites upstream of the adjacent Rv3230c (oxidoreductase), and a cluster of 3 sites upstream of $R v 2524 c$ (fatty acid synthase). This is the second highest-scoring new motif identified (Table 7 ). This motif shows up as one of the top motifs associated with the clusters of genes upregulated under saturated fatty acid conditions (specifically palmitate).

\section{Conclusion}

To better understand $M t b$, we performed a comparative analysis of 31 organisms from the Tuberculosis Database. We studied the evolution of protein families and metabolic pathways, looked for proteins with evidence 
A

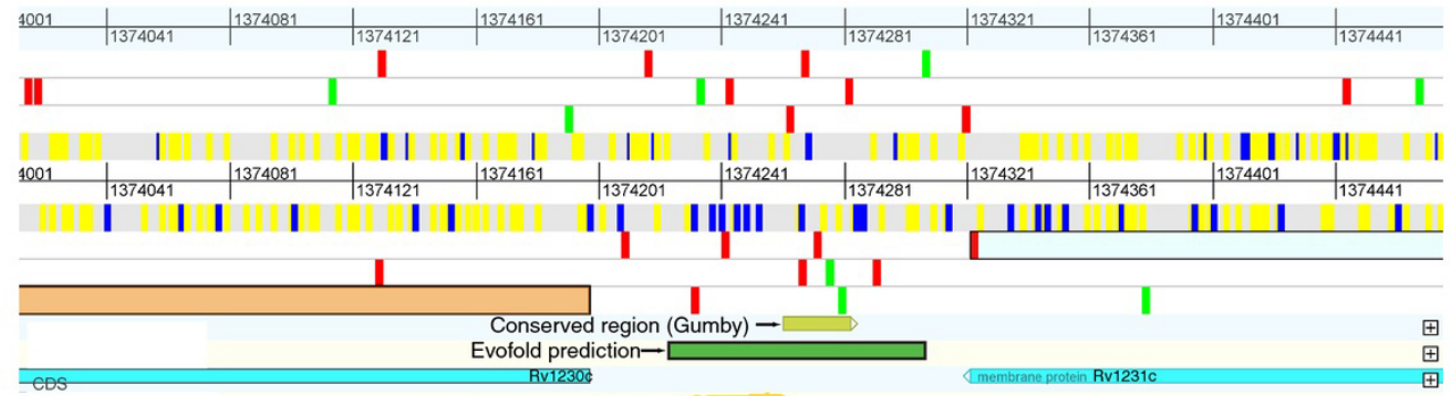

RNAseq data (pileup) -
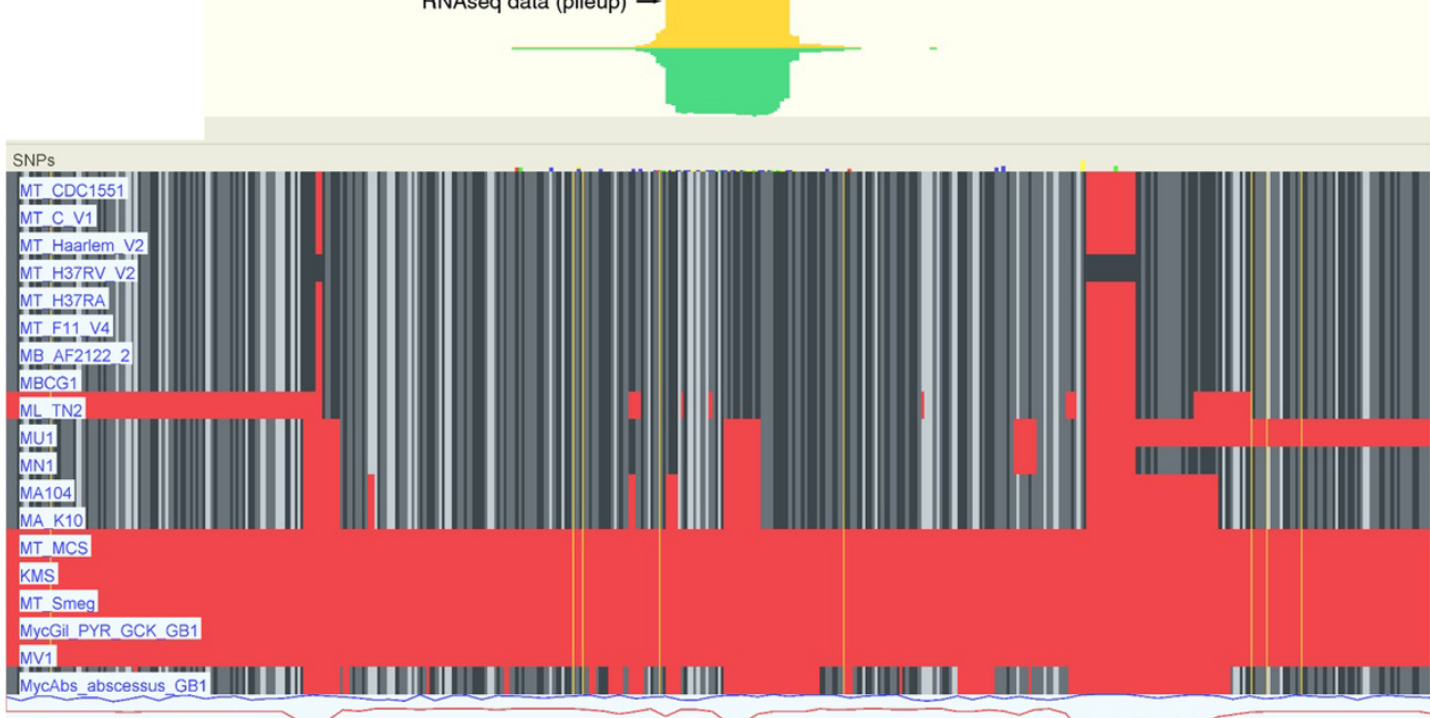

B

RNA1 (59bp)

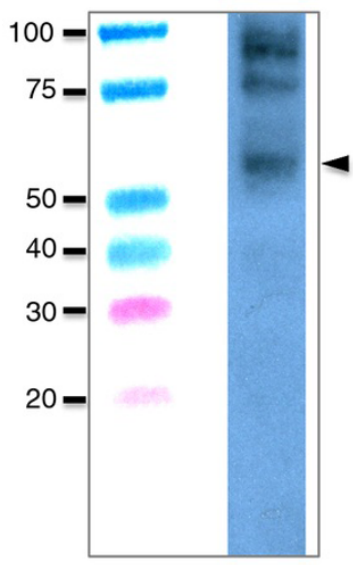

RNA2 (47bp)

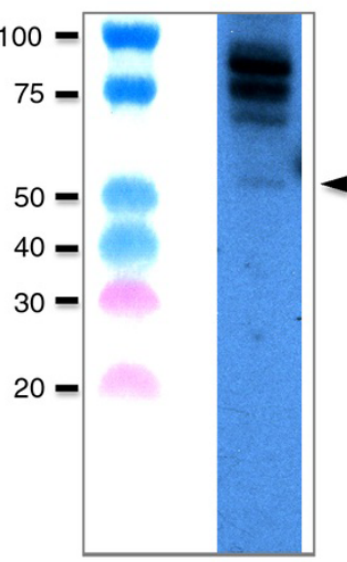

RNA3 (86bp)

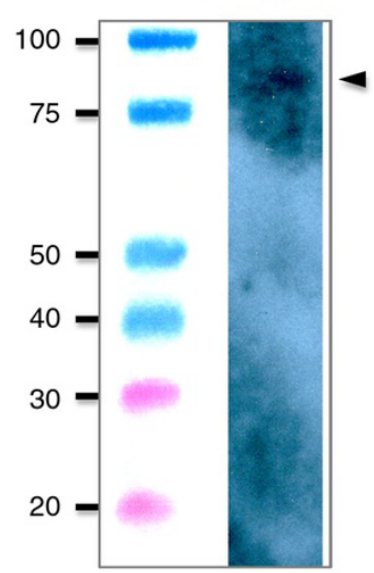

RNA9 (42bp)

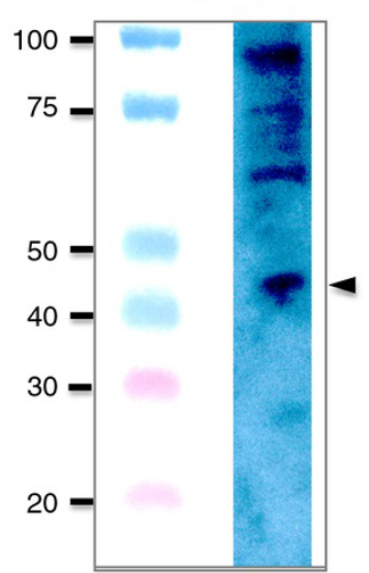

Figure 5 New predicted RNAs. a) An example of a new predicted RNA. This is the RNA2 in Table 6. This figure shows a screenshot from the GenomeView Browser [64]. The light blue bars show the coding regions (Rv1230c and Rv1231); the tan bar shows the conserved region predicted by Gumby [65]; and the green bar shows the region predicted to fold by Evofold [66]. The yellow and green plots in the center show the RNA-seq data. Green signifies reads from the negative strand, and yellow shows the total reads (positive and negative strands). The multiple alignment is shown on the bottom (darker grey signifies a higher degree of conservation; red signifies no alignment at that position). You can see that this predicted RNA region is conserved through M. avium. The rulers at the top show the gene structure. Small red squares show where stop codons are present all six reading frames, indicating that this intergenic region is unlikely to be a protein-coding region missed in the annotation. b) Northern blots validating four of the new, predicted small RNAs (RNA1, RNA2, RNA3, and RNA9 in Table 6). 
Table 6 Top 12 predicted RNAs, ranked by their RPKM score

\begin{tabular}{|c|c|c|c|c|c|c|c|c|c|c|c|c|}
\hline \multirow{3}{*}{ id } & \multicolumn{8}{|c|}{ Conserved region in $M t b H 37 R v^{1}$} & \multicolumn{4}{|c|}{ Region in M. Smegmatis ${ }^{3}$} \\
\hline & \multirow{2}{*}{$\begin{array}{l}\text { start } \\
1612987\end{array}$} & \multirow{2}{*}{$\begin{array}{l}\text { Orient-ation }^{5} \\
-+\end{array}$} & \multirow{2}{*}{$\begin{array}{l}\text { length } \\
58\end{array}$} & \multirow{2}{*}{$\begin{array}{l}\text { \# reads } \\
1013 \\
\end{array}$} & \multirow{2}{*}{$\begin{array}{l}\text { RPKM } \\
69526 \\
\end{array}$} & \multirow{2}{*}{$\begin{array}{l}\text { Evo-fold }^{2} \\
Y\end{array}$} & \multicolumn{2}{|c|}{ Genes flanking the intergenic region } & \multirow{2}{*}{$\begin{array}{l}\text { Start } \\
756567\end{array}$} & \multirow{2}{*}{$\begin{array}{l}\text { Stop } \\
756626 \\
\end{array}$} & \multirow{2}{*}{$\begin{array}{l}\text { \# reads } \\
100 \\
\end{array}$} & \multirow{2}{*}{$\begin{array}{l}\text { RPKM } \\
626 \\
\end{array}$} \\
\hline & & & & & & & Rv1435c (secreted protein) & RV1436 (GAPDH) & & & & \\
\hline $\mathrm{RNA}^{4}$ & 1374224 & - & 46 & 567 & 30071 & Y & Rv1230c (membrane prot.) & Rv1231c (membrane prot.) & - & - & & - \\
\hline $\mathrm{RNA3}^{4}$ & 1393055 & - & 85 & 111 & 9251 & Y & RV1248c (sucA) & Rv1249C (membrane prot.) & 5147110 & 5147242 & 173 & 489 \\
\hline RNA4 & 483829 & -++ & 49 & 55 & 2139 & Y & Rv0403c (membrane prot. mmpS1) & Rv0404 (fadD30) & - & - & & - \\
\hline RNA5 & 1200514 & -++ & 93 & 81 & 2055 & Y & RV1075c (exported protein) & RV1076 (lipase lipU) & 5363400 & 5363474 & 10 & 50 \\
\hline RNA6 & 987053 & -++ & 92 & 174 & 6767 & Y & Rv0887c (cons. Hypo. prot) & Rv0888 (hyp. Exported prot.) & - & - & & - \\
\hline RNA7 & 1810184 & +++ & 44 & 517 & 9280 & Y & Rv1610 (cons. membrane protein) & Rv1611 (trpC) & 3296996 & 3297034 & 291 & 2804 \\
\hline RNA8 & 3587635 & -++ & 56 & 83 & 6917 & $\mathrm{~N}$ & Rv3210c (cons. hypo. prot.) & Rv3211 (rh|E) & 2009575 & 2009665 & 6 & 25 \\
\hline $\mathrm{RNA9}^{4}$ & 4224925 & -+ & 41 & 502 & 24405 & $\mathrm{~N}$ & Rv3778c (aminotransf.) & Rv3779 (membrane prot.) & 6420618 & 6420674 & 36 & 237 \\
\hline RNA10 & 659351 & +++ & 39 & 58 & 1829 & Y & Rv0567 (methyltransferase) & Rv0568 (сур135B1) & - & - & & - \\
\hline RNA11 & 1794708 & -++ & 48 & 375 & 18231 & Y & Rv1593c (cons. hypo. prot) & Rv1594 (nadA) & 3277552 & 3277599 & 70 & 548 \\
\hline RNA12 & 2447526 & - & 74 & 332 & 9684 & Y & Rv2185c (cons. hypo. prot) & Rv2186c (cons. hypo. prot) & 4335086 & 4335137 & 111 & 802 \\
\hline
\end{tabular}

${ }^{1}$ Conserved intergenic regions determined by Gumby.

${ }^{2}$ Indicates whether this region is predicted to fold by Evofold.

${ }^{3}$ Region in M. smegmatis that aligns with the conserved region in Mtb, and its corresponding RPKM value.

${ }^{4}$ Tested experimentally

${ }^{5}$ Orientation relative to neighboring genes. The first and last characters give the strands of the flanking genes; the middle character gives the strand for the predicted RNA. 
Table 7 Motifs passing our set of stringent filters, ranked by their degree of conservation

\begin{tabular}{|c|c|c|c|c|c|c|c|c|}
\hline$k^{a}$ & Cluster \# & Motif & MAP score ${ }^{b}$ & Specificity $^{c}$ & Known $^{d}$ & Palind-romicity ${ }^{e}$ & Conser-vation $^{f}$ & Motif Logo ${ }^{9}$ \\
\hline 100 & 71 & 1 & 65.6 & $1.8 \mathrm{E}-29$ & KstR & 0.93 & 46 & 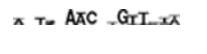 \\
\hline 250 & 179 & 1 & 88.6 & $4.8 \mathrm{E}-26$ & KstR & 0.71 & 43 & AACX_-OTT_IAטX \\
\hline 50 & 35 & 1 & 87.4 & $1.8 \mathrm{E}-19$ & KstR & 0.79 & 40 & $\pi$ DE AAcutGTI. $\pi$ \\
\hline 200 & 182 & 1 & 94.2 & $5.7 \mathrm{E}-28$ & KstR & 0.80 & 36 & 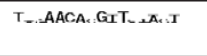 \\
\hline 100 & 73 & 2 & 31.3 & $1.5 \mathrm{E}-32$ & IdeR & 0.85 & 30 & $=x$ Aage $-A-C x \quad-x$ \\
\hline 100 & 49 & 15 & 16.3 & $2.8 \mathrm{E}-18$ & KstR & 0.71 & 29 & $1-A_{A: 2}+O D T$ \\
\hline 250 & 112 & 1 & 25.5 & $2.1 \mathrm{E}-25$ & DosR & 0.76 & 21 & $\mathrm{GGG}_{\mathrm{C}} \mathrm{X}_{x} \mathrm{G}_{\mathrm{T}} \mathrm{C}_{\Omega}$ \\
\hline 100 & 80 & 1 & 15.0 & $2.2 \mathrm{E}-14$ & & 0.92 & 21 & 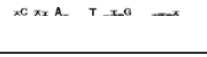 \\
\hline 50 & 29 & 1 & 15.0 & $2.2 \mathrm{E}-14$ & & 0.92 & 21 & $X$ TACs $=\pi \approx A T A$ \\
\hline 50 & 23 & 31 & 21.7 & $6.7 \mathrm{E}-24$ & & 0.71 & 18 & $\pi \mathbb{A} \quad-$ II $\ldots$ AA $=I$ \\
\hline 200 & 47 & 64 & 7.2 & $1.2 \mathrm{E}-15$ & & 0.75 & 16 & $x=A A=T I x$ \\
\hline 250 & 87 & 1 & 22.1 & $1.5 \mathrm{E}-13$ & ZurB & 0.94 & 16 & $G A x \bar{x} \bar{a} x=T T I T C_{x} x$ \\
\hline 200 & 6 & 1 & 16.3 & $2.0 \mathrm{E}-12$ & IdeR & 0.70 & 16 & 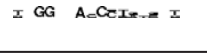 \\
\hline 200 & 184 & 19 & 12.1 & 4.7E-13 & & 0.75 & 16 & $=\bar{\alpha}=\bar{\alpha} T I \ldots \ldots A I A$ \\
\hline 250 & 123 & 18 & 14.5 & $3.7 \mathrm{E}-11$ & & 0.82 & 16 & $A=x G C G G C G C_{2}$ \\
\hline 250 & 224 & 1 & 26.9 & $6.2 \mathrm{E}-24$ & DosR & 0.73 & 15 & $\bar{A} G G G \underline{C}-\dot{\sim}-G_{\mu} C_{\subseteq}$ \\
\hline 200 & 46 & 3 & 19.8 & $1.6 \mathrm{E}-12$ & & 0.78 & 15 & IGTTCGA. .. \\
\hline 100 & 5 & 25 & 12.4 & $3.8 \mathrm{E}-15$ & & 0.71 & 14 & $\approx T_{x \bar{x}}=-\pi T_{\varepsilon A}$ \\
\hline 200 & 120 & 62 & 15.3 & $2.0 \mathrm{E}-14$ & & 0.74 & 14 & $x \in x=A \quad T-I-G \quad-x$ \\
\hline 200 & 71 & 9 & 16.6 & $2.3 \mathrm{E}-16$ & & 0.75 & 14 & CGC $-\Phi C \Theta G C G G$ \\
\hline 200 & 195 & 1 & 25.4 & $7.2 \mathrm{E}-26$ & DosR & 0.76 & 14 & $\pi_{-} G G_{-}=A \mathbb{A} G C_{C}$ \\
\hline 50 & 48 & 1 & 68.8 & $6.4 \mathrm{E}-35$ & DosR & 0.86 & 13 & $\pi \in G G C, \pi G \pi \propto$ \\
\hline 100 & 74 & 1 & 66.9 & $3.6 \mathrm{E}-34$ & DosR & 0.88 & 13 & $\bar{A} G G G C \times X G X$ \\
\hline 50 & 23 & 12 & 26.8 & $5.0 \mathrm{E}-22$ & & 0.73 & 13 & A $A T_{-I} \quad$ AI $x=$ \\
\hline 250 & 89 & 1 & 46.636 & 4.0E-20 & & 0.75 & 12 & 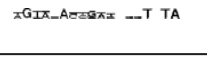 \\
\hline 100 & 81 & 84 & 6.4 & $2.3 \mathrm{E}-16$ & & 0.71 & 12 & 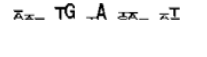 \\
\hline 250 & 92 & 6 & 5.7 & $3.7 \mathrm{E}-17$ & DosR & 0.73 & 12 & 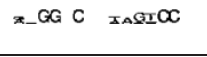 \\
\hline 100 & 52 & 91 & 9.7 & $1.5 \mathrm{E}-18$ & & 0.76 & 11 & $-x+x=A \approx X-I x$ \\
\hline 200 & 91 & 1 & 47.1 & 4.7E-20 & & 0.70 & 10 & GIA-AE_-_IEG_T TA \\
\hline 50 & 36 & 43 & 34.8 & 4.6E-30 & & 0.72 & 10 & $A_{x} \subseteq x-c x A T \quad-\quad=A=I$ \\
\hline 100 & 42 & 4 & 15.3 & $2.8 \mathrm{E}-17$ & & 0.70 & 10 & $\bar{A}-\approx A A_{-}=T_{L}$ \\
\hline 200 & 80 & 9 & 8.5 & 4.0E-13 & & 0.72 & 10 & C $\quad A G=\quad G=T A=e$ \\
\hline 50 & 43 & 7 & 15.7 & 8.7E-12 & & 0.72 & 10 & $\dot{\alpha}=\varepsilon A A T T T_{i}$ \\
\hline 50 & 36 & 21 & 48.5 & $5.3 \mathrm{E}-12$ & & 0.71 & 10 & $I C_{-} \bar{A}-A I C_{\bar{A}}-G A_{I}$ \\
\hline 200 & 26 & 17 & 7.5 & $2.1 \mathrm{E}-12$ & & 0.70 & 9 & STrs_CxG_cas \\
\hline
\end{tabular}


Table 7 Motifs passing our set of stringent filters, ranked by their degree of conservation (Continued)

\begin{tabular}{|c|c|c|c|c|c|c|c|}
\hline 50 & 6 & 61 & 6.3 & $1.2 \mathrm{E}-11$ & 0.73 & 9 & $\overline{A A C A} \simeq \mathrm{II}=\mathrm{x}$ \\
\hline 50 & 11 & 43 & 13.7 & 1.4E-11 & 0.72 & 14 & 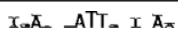 \\
\hline \multicolumn{8}{|c|}{${ }^{\mathrm{a}} \mathrm{k}$ indicates the value of $\mathrm{k}$ in the $\mathrm{k}$-means clustering process $(50,100,200$, or 250$)$} \\
\hline \multicolumn{8}{|c|}{${ }^{\mathrm{b}} \mathrm{MAP}$ score indicates the AlignACE MAP score [76] } \\
\hline \multicolumn{8}{|c|}{ 'Specificity score [77] } \\
\hline \multicolumn{8}{|c|}{${ }^{d}$ CompareACE score $\geq 0.7$ to the alignment for this known motif } \\
\hline \multicolumn{8}{|c|}{${ }^{\mathrm{e} C} \mathrm{CompareACE}$ score to its reverse complement } \\
\hline \multicolumn{8}{|c|}{ fnumber of ScanACE hits in the genome that are conserved in $\geq 8$ genomes } \\
\hline${ }^{\mathrm{g}} \mathrm{se}$ & e los & & & & & & \\
\hline
\end{tabular}

of selection, and searched for new noncoding RNAs and transcription factor binding site motifs.

The most striking features of our analysis are related to lipid metabolism and its regulation. In addition to observing a general expansion of lipid metabolism genes in the Mycobacteria and Rhodococcus, we observe increased expansions of genes related to saturated fatty acid metabolism in the pathogenic Mycobacteria compared to the soil-dwelling Mycobacteria. We also note differences in evolutionary profiles for catabolic and anabolic lipid metabolism genes, and evidence for positive selection in lipid metabolism genes. The cis-regulatory elements bound by the KstR protein, a known regulator of lipid/cholesterol metabolism, are among the strongest, most highly conserved noncoding signals across the Mycobacteria. Both KstR and its binding sites are highly conserved, appearing at the last common ancestor between Rhodococcus and the Mycobacteria.

Within our set of organisms, we examine the evolution of pathogenicity, moving from the soil-dwelling Mycobacteria up to the intracellular parasites of the $M t b$ complex. We see expansions of many known gene families related to pathogenicity (PE/PPE genes, antibiotic resistance genes, genes involved in the synthesis of the mycolic acid coat, MCE genes, and Esx genes). By similarity of phylogenetic profiles, we can predict likely candidates for novel gene families related to pathogenicity. For example, we see similar expansions in gene families related to biosynthesis of molybdopterin. We further observe evidence of positive selection on molybdenum-related genes, providing further support for the importance of molybdenum in these pathogens. On the branch leading to the pathogenic Mycobacteria, we also observe evidence for positive selection in genes related to replication, recombination, and repair. It is possible that these DNA repair-related processes give the pathogenic Mycobacteria an advantage when dealing with the assault on its DNA by macrophage-generated reactive oxygen and nitrogen intermediates.

Our whole-genome alignments, coupled with RNA-seq and microarray data, allowed us to predict novel noncoding features, including small RNAs (four of which we have validated experimentally), and potential transcription factor binding sites.

The main forces driving genome evolution in prokaryotes include gene genesis, lateral gene transfer, and gene loss. Our analysis of protein evolution using SYNERGY does not examine whether orthogroups appearing have arisen by lateral gene transfer or by gene genesis involving duplication and divergence from other orthogroups. A detailed comparison to categorize these orthogroup appearances according to lateral or vertical gene transfer is beyond the scope of this study, but other studies indicate that lateral gene transfer has played a significant role in Mycobacterial evolution and the evolution of pathogenesis [79-83].

A recent paper suggests that the Mycobacterial genome has been shaped by a biphasic process involving gene acquisition (including lateral gene transfer) and duplications followed by gene loss [79]. Other studies report numerous genes, including a large number involved in lipid metabolism, that have been acquired by horizontal gene transfer at different phylogenetic strata and have led to the emergence of pathogenesis in $M t b$ $[80,81]$. Previous studies indicate a possible more ancient lateral gene transfer of fatty acid biosynthesis genes from $\alpha$-proteobacteria to actinobacteria [84]. However, genetic studies show that the $M t b$ complex and pathogenic Mycobacteria do not exchange genetic material frequently $[85,86]$, so there is limited lateral gene transfer within the $M t b$ complex.

We are currently performing high-throughput Chromatin Immunoprecipitation (ChIP)-Seq experiments in several different Mycobacteria, including Mtb, M. smegmatis, and $M$. vanbaalenii [87]. We plan to integrate the information obtained from our comparative analysis with data coming from these high-throughput experiments, as well as other 'omic datasets, using a systems biology approach. This will enable construction of gene regulatory networks for $M t b$, and examination of their evolution across species.

\section{Methods}

\section{Genome sequences}

The 31 organisms used in our analysis are described in Table 1 . These genome sequences are all contained in 
the TB database (TBDB) [75]. The three unpublished sequences generated at the Broad Institute (M. tuberculosis F11, M. tuberculosis Haarlem, and M. tuberculosis $C)$ are high-quality genome sequences. $M$. tuberculosis F11 and M. tuberculosis Haarlem are finished, and $M$. tuberculosis $C$ has $6.7 \times$ coverage and 4 scaffolds. The Broad Institute sequencing read pipeline interacts with the sample management system to ensure the read is associated with the correct sample. Vector identification, length checks and quality clipping were performed on all reads. Contamination checks and organism checks were also performed using a kmer-based algorithm that can compare sequence to a profile from any organism.

\section{Defining protein families and constructing phylogenetic trees}

The SYNERGY algorithm [27,28] was applied to the 31 genomes in Table 1. SYNERGY organizes groups of genes across organisms into orthogroups, or groups of orthologs and paralogs, which consist of all the genes descended from a single ancestral gene in the species' last common ancestor. SYNERGY also associates orthogroups with a gene tree, from which we can derive an "extended phylogenetic profile", showing the gene copy number in each extant organism and at each ancestral node. Importantly, by reconciling an organism tree with each gene tree, SYNERGY provides an evolutionary scenario for each gene tree predicting where all losses, gains, and duplications occurred in its evolution. These lists of losses, gains, and duplications contain actual evolutionary events, as well as artifacts caused by genes that could not be properly categorized by SYNERGY. However, we observe that SYNERGY is effective at properly categorizing genes into orthogroups, and the SYNERGY orthogroups were very useful in our analysis. Analysis of the 31 genomes resulted in a total of 32,505 orthogroups, including those containing single genes from only a single genome (below). There were 177 "uniform" (1:1:1:1 ...) orthogroups representative of some of the most conserved and indispensible housekeeping genes. Additional file 4: Figure S3 summarizes the SYNERGY orthogroups.

We started running SYNERGY using an initial phylogenetic tree generated using orthologs based on bidirectional best BLAST hits. The list of uniform orthogroups from the first SYNERGY run was used to construct a refined phylogenetic tree. SYNERGY was then re-run using the refined phylogenetic trees. To generate our final phylogenetic tree, the final set of 177 31-way orthologs (31-way uniform orthogroups from the SYNERGY analysis) were aligned according to their nucleotide sequences with CLUSTALW [88] and concatenated, distances were computed with Phylip's
DNADIST algorithm [89], and Phylip's FITCH algorithm was used to create the tree.

Because of the similarity of the genomes within the $M t b$ complex, we were not able to resolve the phylogeny using only these 177 proteins that are uniform across all 31 organisms. In order to better resolve the tree within the $M t b$ cluster, we computed a separate tree using 1747 orthogroups that are uniform across the $M t b$ cluster and $M$. ulcerans, which we used as an outgroup. Using this expanded gene set, we were able to resolve the tree for the $M t b$ cluster.

Bootstrap analysis was performed to validate tree topologies. Phylip's SEQBOOT was used to create 1000 bootstrap input replicates for each tree. Phylip's CONSENSE was used to obtain a bootstrap tree (Additional file 5: Figure S4)

\section{Metabolic pathways and functional groups}

EFICAZ [90] was used to assign EC numbers for proteins in all 31 organisms. Metabolic pathways were constructed in Biocyc [91,92]. An orthogroup was considered to be part of a metabolic pathway if any of its component genes had been identified as part of that pathway using this pipeline.

We obtained the Gene Ontology (GO) [29] and GO Slim terms for each of the 31 organisms using BLAST2GO [93]. PFAM assignments [30] were taken from http://www.tbdb.org[75]. An orthogroup was associated with a GO, GO Slim, or PFAM descriptor if greater than half of its protein members were associated with that descriptor.

For each node in the phylogenetic tree, we tabulated orthogroups lost, gained, or duplicated. Using GO terms, GO Slim terms, and PFAM domain groupings with less than 500 members, we calculated over-representations within losses, gains, and duplications each of these groupings at each node using the hypergeometric test. A complete summary of gains, losses, and duplications for all nodes in the phylogenetic tree is available on our supplementary information website.

\section{Phylogenetic profiles}

Extended phylogenetic profiles for each category (metabolic pathways, GO terms, GO Slim terms and PFAM categories) were obtained from SYNERGY output by summing the phylogenetic profiles from their component orthogroups. We define a category-level phylogenetic profile as the sum of its component orthogrouplevel phylogenetic profiles. The evolution of each of these categories can be quickly visualized on our website. Since genes with the same phylogenetic profile can be linked functionally [94], the webpage for each category contains a link to other categories with similar 
phylogenetic profiles (Methods). Categories with the most similar profiles were obtained by calculating Euclidean distances to all other profiles.

Instances of expanded or missing pathways across the 31 organisms will have non-uniform pathway-level phylogenetic profiles. Thus we tabulated the number of genes in each genome for each category, and automatically searched for gene categories whose copy number (normalized for genome size) had the most non-uniform distribution across the 31 organisms in order to identify the most significant examples of expansions or losses. To identify categories with bimodal properties (such as a categories with a loss or a large expansion on only certain branches of the phylogenetic tree), we clustered each profile into two groups and looked for the pathways with the greatest separation between the two clusters. We used $k$-means $(k=2)$ to cluster the profile vectors, and compared the intra- and inter-cluster point-to-centroid distances to find the clusters with the greatest separation. We ranked categories by this separation to find bimodal categories. We further select those that have at least five organisms in the smallest of the two clusters, and an average of at least five genes per genome. $\mathrm{P}$-values are calculated from a T-test between the values for the two groups, with Bonferroni correction applied. In our Supplementary Information website we list those categories with $\mathrm{p}<0.05$, ranked by the difference between their inter- to intra-centroid distances. When we select the metabolic pathways, PFAM domains, and GO terms with the most non-uniform category-level phylogenetic profiles overall, we find that many of the top categories are lipid metabolism-related categories expanded in the Mycobacteria.

We also measured the similarity between evolutionary profiles to find the PFAM categories and GO terms with the biggest difference between pre-defined sets of organisms. For example, we compared both the $M t b$ complex and a group consisting of other pathogenic Mycobacteria to the set of soil-dwelling Mycobacteria in order to examine the evolution of soil-dwelling, free-living Mycobacteria into more pathogenic Mycobacteria that require a host to survive. We used the following categories:

1. All Mycobacteria (excluding M. leprae because of its massive gene loss).

2. All non-Mycobacteria in our set (excluding Nocardia and Rhodococcus because of their similarity to Mycobacteria)

3. $M t b$ complex (8 organisms)

4. Other pathogenic Mycobacteria (M. ulcerans, M. avium 104, M. avium K10, M. marinum).

5. Soil-dwelling Mycobacteria that do not require a host (M. sp. MCS, M sp. KMS, M. smegmatis, M. vanbaalenii, M. abscessus, M. gilvum).

\section{R. jostii RHA1 and N. farcinia}

We calculated differences between two sets of organisms exactly as we calculated distances between clusters (above). However, rather than using different clusters of organisms determined by k-means clustering, we used these pre-defined clusters of organisms. We looked at distances between the following sets of organisms: 1-2, 3-4, 3-5, 3-6, 4-5, 4-6, 5-6. For each PFAM domain or GO term represented in at least two organisms in these pairings, we calculated p-values for the differences between the profile values by $\mathrm{T}$-test (Bonferroni-corrected by the number of PFAM domains represented in that set of organisms) and computed inter-and intra-centroid distances (as described in the above paragraph). We compiled lists of those that are most expanded and a list of those most contracted across these pairings. On our website we have included complete lists of PFAM categories, including those that do not make the strict Bonferroni-corrected p-value cutoff. Many potentially interesting expansions do not make the overly conservative Bonferroni-corrected p-value cutoff $[95,96]$.

\section{Motif discovery}

Using a compendium of 946 microarray experiments from the TB database [75], we used several different clustering methods to generate predicted regulons. We searched the upstream regions of these regulons for shared transcriptional regulatory motifs. We clustered microarray data by hierarchical and k-means clustering. Because real regulons can be of varying sizes, we performed $\mathrm{k}$-means with $\mathrm{k}=50,100,200$, and 250, then used all the resulting clusters for further analysis. We found that the clusters obtained from hierarchical clustering were not very useful because their size distribution did not approximate that of real regulons as well as those from k-means; therefore we did not analyze clusters from hierarchical clustering further.

We used AlignACE [97] to search the upstream regions of the genes in these clusters for motifs. We used the methods for operon prediction, selecting upstream regions, and applying AlignACE to prokaryotic genomes as described in McGuire et al. [77]. Briefly, because of the presence of operons in prokaryotes, we must choose the upstream region of the operon head rather than the region immediately upstream of the gene of interest. Since it is more important to include the correct region than to erroneously include extra incorrect regions, we use a loose operon definition and include sequences for several different possibilities if there is any ambiguity. We look upstream of our gene of interest and select all intergenic sequences until we encounter either a divergent intergenic region or an intergenic region longer than $300 \mathrm{bp}$. 
Motifs of interest were selected by applying a set of filters: specificity score [77], quality of alignment (AlignACE MAP score) [97], palindromicity [77], and conservation. To determine the degree of conservation, a search matrix was constructed for each motif. Each of the other genomes was searched with this search matrix using CompareACE, and N-way conserved sites were identified. N-way conserved hits are hits identified upstream of orthologous genes in $\mathrm{N}$ genomes, where orthology is defined by membership in the same SYNERGY orthogroup. To select interesting motifs we required specificity score $<1 \mathrm{e}-10$, palindromicity $>0.7$, MAP score $>5$, and at least 8 sites conserved in 8 genomes.

Motifs were compared to a library of search matrices for 9 known $M t b$ motifs (Acr, Crp, CsoR, DosR, FurA, IdeR, KstR, MprAB, and ZurB), as well as a library of 55 E. coli motifs [98] and 22 Corynebacterial motifs [99]. Comparison of motifs was done using CompareACE [76].

\section{Defining groups based on expression under different lipids}

We separated the experiments in our compendium of $M t b H 37 R v$ microarray experiments into separate conditions based on what nutrients were present in their growth conditions (focusing on different lipid conditions, because of the observed importance of lipid metabolism in these organisms). The following categories were used (the number of experiments in each category is shown in parentheses): Palmitic acid (168), Oleic acid (102), Arachidonic and Eicosatetraynoic acids (76), Linoleic acid (41), Eicosatetraynoic acid (13), Ceramide (4), Nordihydroguaiaretic (3), Cholesterol (2), Glucose (1), KstR knockout (1), KstR knockout with cholesterol added (1).

Within each experiment, we extracted a list of genes upregulated 1.5 and 2 standard deviations above the mean. For each category, we considered a gene to be upregulated if it was upregulated in more than $50 \%$ of the experiments making up that category. We then searched for genes that were only upregulated under certain conditions or sets of conditions.

We looked at the evolution of these sets of $M t b$ $H 37 R v$ genes by taking the other members of their orthogroups across all 31 other organisms. Evolution of these groups can be visualized in our supplementary information http://www.broadinstitute.org/ftp/pub/seq/ msc/pub/SYNERGY/index.html.

\section{$\mathrm{d}_{\mathrm{N}} / \mathrm{d}_{\mathrm{s}}$ Analysis}

We used PAML to calculate $d_{N} / d_{S}$ values according to several different evolutionary models [100,101]. Since orthogroups contain paralogs as well as orthologs, we used the gene trees output from SYNERGY when running PAML. Some orthogroups may contain single-copy orthologs in only two closely related organisms, whereas others could contain paralogs in all 31 organisms.

For the basic model, we used the following parameters: model $=0$ and getSE $=1$ (to calculate standard errors). This simple evolutionary model gives one value of $d_{N} / d_{S}$ for each orthogroup, averaged over all lineages as well as all positions in the gene [102]. While this model does not reflect the evolutionary history that has taken place, it is nevertheless a very blunt yet efficient tool for observing selection.

To gain insight into the evolution of the three major clades of the phylogenetic tree we also used a "branch model" where a different $d_{N} / d_{S}$ value is allowed on a "foreground" branch (but $\mathrm{d}_{\mathrm{N}} / \mathrm{d}_{\mathrm{S}}$ is averaged along positions in the protein) $[103,104]$. This was done in PAML by using "Model $=2$ ". We compared this model to the basic model using a log-likelihood $\chi^{2}$ test with d.o.f. $=1$. For each of the three foreground branches, we used a Bonferroni correction equal to the number of orthogroups present at the branch. We ran this separately for three different "foreground" branches on the phylogenetic tree (labeled in Figure 1): A) The branch leading to the $M t b$ complex; B) The branch leading to pathogenic Mycobacteria; and C) The branch leading to soil-dwelling, non-pathogenic Mycobacteria. The loglikelihood model that we use here compares this branch model to the simple model with a single value of $d_{N} / d_{S}$ described above, and tests whether the model allowing $\mathrm{d}_{\mathrm{N}} / \mathrm{d}_{\mathrm{S}}$ to differ on the foreground branch fits the data better than the basic model.

Branch-site models allow $\mathrm{d}_{\mathrm{N}} / \mathrm{d}_{\mathrm{S}}$ to vary across branches of the tree and among sites in the protein. We also used the branch-site model of Zhang and Nielsen [100] using Model $=2$, NSsites $=2$, and fix_blength $=2$. We used the model $=0$ calculations to determine branch lengths for the branch-site model calculations to save computational time. We compared the results for a subset of the orthogroups with and without fixed tree lengths and determined there was little difference in the results). We chose the same three sets of branches (AC) that we used for the branch model described above. We compared this model to the corresponding null model using a log-likelihood $\chi^{2}$ test with d.o.f. $=1$ [100]. For each of the three foreground branches, we used a Bonferroni correction equal to the number of orthogroups present at the branch. The branch-site model was the most informative.

We calculated the functional group over-representations separately for each functional group dataset. These datasets included 21 COG categories, 168 KEGG categories, 749 metabolic pathways, and 7 additional Mycobacteria-specific groupings (PE genes, PPE genes, toxinantitoxin genes, DosR regulon, esx genes, Rv0474 regulon, and the KstR regulon). We multiplied the 


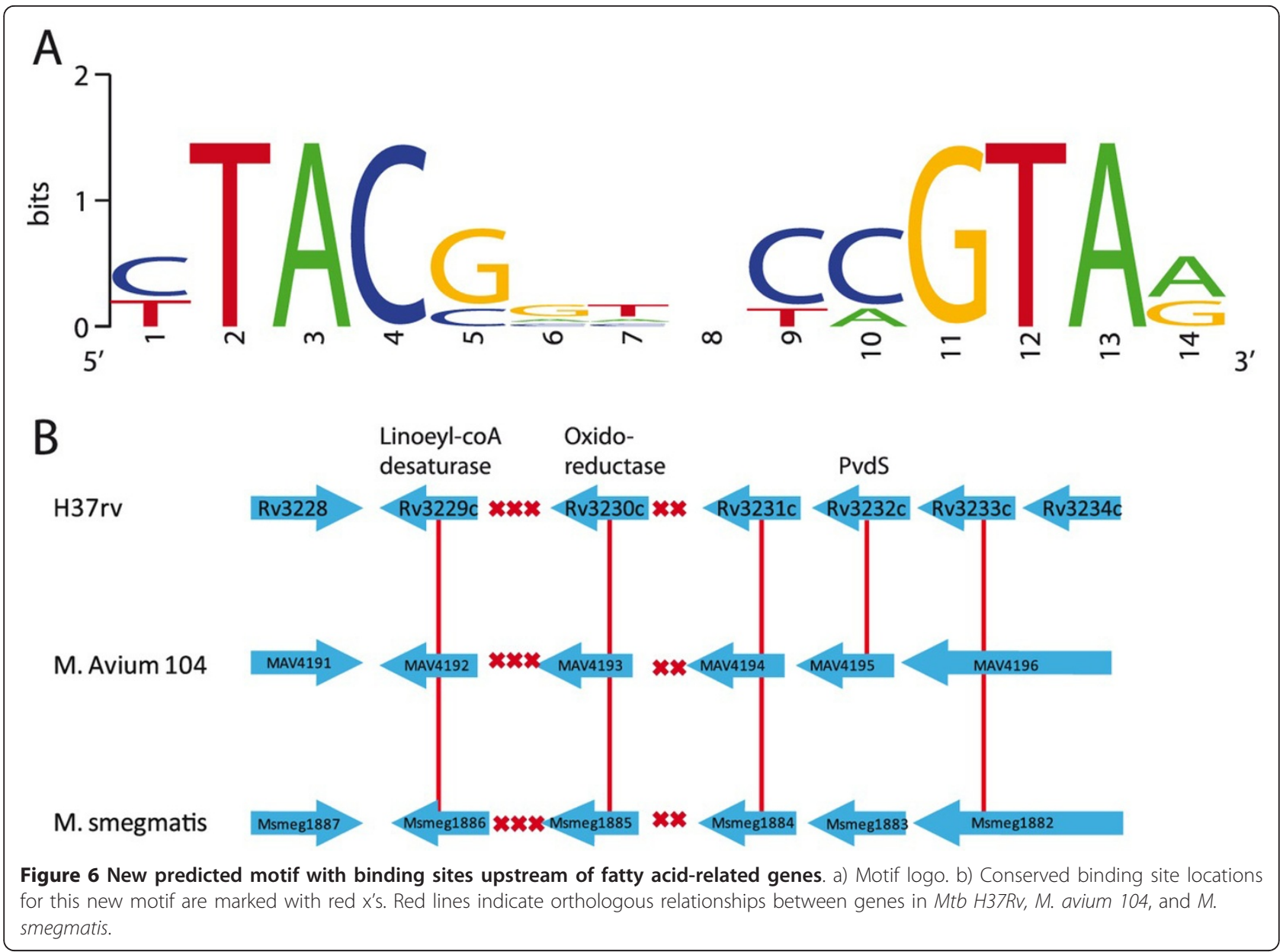

hypergeometric p-values by a Bonferroni correction equal to the number of categories or tests performed.

\section{Generating multi-genome alignments}

We constructed whole-genome alignments of all 31 organisms, as well as subsets including only Mycobacterial organisms, and organisms within the $M t b$ complex. These alignments can be downloaded from our website. Our whole genome multiple alignments reveal unannotated stretches of conservation in noncoding regions including transcription factor binding sites in promoter regions, noncoding RNAs, and mis-annotated proteins.

To generate whole-genome multiple alignments, we first aligned the reference genome to each target genome in a pairwise manner. The process of pairwise whole-genome alignment consists of using PatternHunter [105] to identify anchors of local alignment, grouping collinear anchors separated by a limited distance into chains, filtering out smaller chains that shadow larger ones, and finally using LAGAN [106] to globally align the entire chain. Once all genomes have been aligned to the reference, we then identified intervals of the reference that map tightly to a single interval of some or all of the target genomes, and we consider these the endpoints of blocks of multiple alignment. These blocks are generally smaller than any precursor pairwise alignment, because a rearrangement or loss of detectable similarity in any genome will truncate the block for all member genomes. We then ran the multiple aligner MLAGAN on each block. Finally, to facilitate searches for constrained regions of the reference, we projected the blocks onto the reference genome, effectively unwinding all genome rearrangements in the target genomes relative to the reference. We visualized the alignments in the GenomeView browser [64].

\section{Selecting conserved regions within the alignments}

We used Gumby [65] to select conserved regions in our multiple alignments using a value of $\mathrm{p}<0.5$. In a multiple alignment of all 19 Mycobacterial genomes, we identified 4697 regions of conservation overlapping coding genes in the reference annotation, and 394 regions in intergenic regions. 
We also used the method of Ruzzo and Tompa [107] to identify conserved regions. Scores were normalized to the background inferred from the 3 rd-base frequencies. For all $H 37 R v$ coding sequences, all bases in the third position were extracted from the 31-way multiple alignment. These were concatenated in a new multiple alignment only containing third bases. From this new multiple alignment we calculated the baseline conservation which is used to normalize the conservation scores for the regular alignment. Both sets of highly conserved regions can be viewed as alignment tracks for the GenomeView browser [64], downloadable on our website.

\section{Predicting RNAs}

We predicted regions likely to form RNAs within the conserved intergenic regions of our multiple alignment of 19 Mycobacteria, using Evofold [66]. We divided the intergenic region into 240-bp segments, tiled by 80 bp, to run Evofold. Looking within intergenic regions, we identified 536 regions with Evofold (regions greater than $5 \mathrm{bp}$ in length with length-normalized folding potential score $>0.2$ ).

We examined these 536 regions, as well as the 394 conserved intergenic regions found by Gumby, to see if any of these showed significant expression in our logphase $M t b$ RNA-seq data. We calculated RPKM [108] values for each of these regions. We examined the regions with RPKM value $\geq 200$ and a number of RNAseq reads $\geq 20$. We eliminated an additional 35 regions which corresponded to known RNAs from the $M t b$ annotation, or RNAs similar to those found in $M$. bovis and Streptococcus [60-63], including 26 tRNAs, 2 riboswitches, and 3 found in other organisms.

To select intergenic regions with high levels of expression that do not correspond to UTRs, we also calculated RPKM values for the $100 \mathrm{bp}$ regions of the flanking genes closest to the intergenic regions. We selected those intergenic regions with the highest ratio of the RPKM value of the region of interest (within the intergenic region) to the RPKM of the start/stop of the flanking genes. We also looked for regions with a gap in expression between the gene and the region of interest. This will eliminate many regions that merely correspond to UTRs, and select for regions that are disproportionately expressed within the intergenic region only. We found this method to be most useful for selecting regions of interest, and successfully enriched our top hits for previously known small RNAs. The top 50 predicted RNAs can be viewed as a track in the GenomeView browser (see Supplementary Information).

We further examined log-phase RNA-seq data from M. smegmatis to confirm that many of the orthologous regions also show expression in $M$. smegmatis.

\section{Strain, media, and culture conditions for RNA-seq}

Mycobacterium tuberculosis $\mathrm{H} 37 \mathrm{Rv}$ and M. smegmatis were grown at $37^{\circ} \mathrm{C}$ in $7 \mathrm{H} 9$ media supplemented with 10\% ADC (Becton Dickinson), 0.2\% glycerol and 0.05\% Tween 80. For log phase, cells were grown to $\mathrm{OD}_{540} 0.2$. Roller bottles were used for culturing M. tuberculosis, and shaker flasks for M. smegmatis.

\section{RNA isolation from in vitro cultures for RNA-seq}

Bacterial pellet from log-phase cultures of M. tuberculosis and M. smegmatis were resuspended in TRIzol reagent (Invitrogen) and immediately transferred to 2 $\mathrm{ml}$ screw-cap tubes containing $0.1 \mathrm{~mm}$ zirconia/silica beads (BioSpec Products). M. tuberculosis cells were lysed using a FastPrep-24 bead-beater (MP Biomedicals) 3 times for 30 seconds each at speed 6. M. smegmatis cells were lysed using MagNalyser (Roche). Samples were kept on ice for 1 min between pulses. The TRIzol extracted RNA was treated twice with DNAse and further purified using RNAeasy kit (Qiagen).

\section{Directional mRNA-seq libraries for RNA-seq}

We generated mRNA-seq libraries for sequencing on Illumina's GA Sequencer (San Diego, CA). $2 \mu \mathrm{g}$ purified RNA was depleted of ribosomal RNA using Ambion's MICROBExpress Kit (Austin, TX) as per manufacture's recommended protocol. The enriched mRNA was used to prepare libraries using Illumina's Directional mRNAseq Library Prep v1.0 protocol. Briefly, 100 ng mRNA was fragmented with cations and heat, end-repaired, adapted by sequential ligation of unique 5-prime and 3prime adapters, reverse transcribed, PCR amplified, and purified using Agencourt's AMPure Beads (Beverly, MA). The libraries were visualized on an Agilent 2100 Bioanalyzer (Santa Clara, CA) and found to have the expected average fragment length of $\sim 250 \mathrm{bp}$.

\section{RNA isolation and Northern Blotting}

Total RNA was isolated from Mtb as described previously [109] with minor modifications. Briefly, logphase cells were pelleted, resuspended in TRIzol (Invitrogen), and transferred to Lysing Matrix B tube (QBiogene). The cells were lysed using MagNalyser (Roche), and RNA extracted with Trizol reagent as instructed by the manufacturer. RNA was treated with Turbo DNase (Ambion) for 30 minutes at $37^{\circ} \mathrm{C}$ twice and purified further using TRIzol solution and 100\% Ethanol.

Total RNA was separated on 10\% TBE-Urea acrylamide gels (Bio-Rad) and electroblotted onto Hybond $\mathrm{N}+$ membranes (GE Healthcare). After UV cross-linking the membranes were pre-hybridized and hybridized with labeled probes at $48^{\circ} \mathrm{C}$ as per the DIG manual (Roche). Probe sequences are CGATGGTCGAAAAGGAACTCGATACGGCTATGCGGTTCT (RNA1), AGTTCACGA 


\section{AACGAAGAAAGAAGCTAAGAAGACATAGGTT (RNA2), GACTGCCAGCAGGCGCCGCGCAATGCG CTTGCAGGACTTC (RNA3), and GGGTGACAT GGCTCAGGGAAGCCCGGGCGGGCTGGGACGT} (RNA9). After hybridization the membranes were washed twice using a low stringency buffer $(2 \times$ SSC, $0.1 \%$ SDS), and a high stringency buffer $(0.1 \times$ SSC, $0.1 \%$ SDS $)$, for 15 and 5 minutes at $48^{\circ} \mathrm{C}$, respectively. The membranes were processed with DIG detection system (Roche) and exposed to X-ray film.

\section{Additional material}

Additional file 1: Supplementary Results [110-130].

Additional file 2: Additional related tetR family regulators (2-3 copies in each environmental Mycobacterium).

Additional file 3: Northern Blots for small RNAs in M. tuberculosis. Additional file 4: Genomes contained in orthogroups.

Additional file 5: Phylogenetic tree showing bootstrap results.

\section{Abbreviations}

Mtb: Mycobacterium tuberculosis; PAH: Polycyclic aromatic hydrocarbons; GO: Gene Ontology; MMR: Mismatch repair.

\section{Acknowledgements}

Jan Baumbach provided known corynebacterial regulatory motif alignments. Lina Faller clustered orthogroups by their phylogenetic profiles. Robert N. Husson helped in obtaining the RNA. Jared Sharp, in Robert N. Husson's laboratory, helped with the RNA prep. IW is the HHMI Fellow at the Damon Runyon Cancer Research Foundation.

\section{Author details}

'Broad Institute, 7 Cambridge Center, Cambridge, MA 02142, USA. ²DOE Joint Genome Institute, Walnut Creek, CA, USA. ${ }^{3}$ Department of Biomedical Engineering, Boston University, Boston, MA, USA. ${ }^{4}$ Departments of Microbiology and National Emerging Infectious Diseases Laboratories, Boston University, Boston, MA, USA. ${ }^{5}$ VIB Department of Plant Systems Biology, Ghent University, Technologiepark 927, 9052 Ghent, Belgium. ${ }^{6}$ Stanford University, Palo Alto, CA, USA. ${ }^{7}$ FLIR, Chem-Bio Detection, 505 Coast Boulevard South, Suite 309, La Jolla, CA 92037, USA. ${ }^{8}$ Department of Systems Biology, Harvard Medical School, 200 Longwood Ave., Boston, MA 02115, USA. 'The Broad Institute, 7 Cambridge Center, Cambridge, MA 02142, USA

\section{Authors' contributions}

AMM performed the analysis and drafted and finalized the manuscript. BW and RR were involved in many aspects of the comparative analysis. STP and SR performed the experimental validation. IW and AR performed the SYNERGY analysis. GD, GKS, RTY, MIM, MJK, and A. Maer provided the $M$. tuberculosis RNA-seq data. TA provided the GenomeView browser. JZ performed the Eficaz and metabolic pathway analyses. JW, PS, and MK constructed multiple alignments. CS worked on the web page. MP worked on motif discovery and network reconstruction. JEG initiated and supervised the study, and revised the manuscript. All authors read and approved the final manuscript.

\section{Competing interests}

The authors declare that they have no competing interests.

Received: 23 September 2011 Accepted: 28 March 2012 Published: 28 March 2012
References

1. World Health Organization, Global Tuberculosis Programme: Global tuberculosis control: WHO report. Geneva: Global Tuberculosis Programme; 2009, v.

2. Cole ST, Brosch R, Parkhill J, Garnier T, Churcher C, Harris D, Gordon SV, Eiglmeier K, Gas S, Barry CE, et al: Deciphering the biology of Mycobacterium tuberculosis from the complete genome sequence. Nature 1998, 393:537-544

3. Camus JC, Pryor MJ, Medigue C, Cole ST: Re-annotation of the genome sequence of Mycobacterium tuberculosis H37Rv. Microbiology 2002, 148:2967-2973.

4. Z Zheng H, Lu L, Wang B, Pu S, Zhang X, Zhu G, Shi W, Zhang L, Wang H, Wang $S$, et al: Genetic basis of virulence attenuation revealed by comparative genomic analysis of Mycobacterium tuberculosis strain H37Ra versus H37Rv. PLoS One 2008, 3:e2375.

5. The Broad Institute. [http://www.broadinstitute.org].

6. Brosch R, Gordon SV, Garnier T, Eiglmeier K, Frigui W, Valenti P, Dos Santos S, Duthoy S, Lacroix C, Garcia-Pelayo C, et al: Genome plasticity of BCG and impact on vaccine efficacy. Proc Natl Acad Sci USA 2007, 104:5596-5601.

7. Garnier T, Eiglmeier K, Camus JC, Medina N, Mansoor H, Pryor M, Duthoy S, Grondin S, Lacroix C, Monsempe C, et al: The complete genome sequence of Mycobacterium bovis. Proc Natl Acad Sci USA 2003, 100:7877-7882

8. Fleischmann RD, Alland D, Eisen JA, Carpenter L, White O, Peterson J, DeBoy R, Dodson R, Gwinn M, Haft D, et al: Whole-genome comparison of Mycobacterium tuberculosis clinical and laboratory strains. J Bacteriol 2002, 184:5479-5490

9. Stinear TP, Seemann T, Pidot S, Frigui W, Reysset G, Garnier T, Meurice G, Simon D, Bouchier C, Ma L, et al: Reductive evolution and niche adaptation inferred from the genome of Mycobacterium ulcerans, the causative agent of Buruli ulcer. Genome Res 2007, 17:192-200.

10. Stinear TP, Seemann T, Harrison PF, Jenkin GA, Davies JK, Johnson PD, Abdellah Z, Arrowsmith C, Chillingworth T, Churcher C, et al: Insights from the complete genome sequence of Mycobacterium marinum on the evolution of Mycobacterium tuberculosis. Genome Res 2008, 18:729-741.

11. Cole ST, Eiglmeier K, Parkhill J, James KD, Thomson NR, Wheeler PR, Honore N, Garnier T, Churcher C, Harris D, et al: Massive gene decay in the leprosy bacillus. Nature 2001, 409:1007-1011.

12. The Institute for Genome Research/The J. Craig Venter Institute. [http:// www.jcvi.org].

13. Li L, Bannantine JP, Zhang Q, Amonsin A, May BJ, Alt D, Banerji N, Kanjilal S, Kapur $\mathrm{V}$ : The complete genome sequence of Mycobacterium avium subspecies paratuberculosis. Proc Natl Acad Sci USA 2005, 102:12344-12349.

14. Joint Genome Institute. [http://www.jgi.doe.gov]

15. Ripoll F, Pasek S, Schenowitz C, Dossat C, Barbe V, Rottman M, Macheras E, Heym B, Herrmann JL, Daffe M, et al: Non mycobacterial virulence genes in the genome of the emerging pathogen Mycobacterium abscessus. PLoS One 2009, 4:e5660.

16. McLeod MP, Warren RL, Hsiao WW, Araki N, Myhre M, Fernandes C, Miyazawa D, Wong W, Lillquist AL, Wang D, et al: The complete genome of Rhodococcus sp. RHA1 provides insights into a catabolic powerhouse. Proc Natl Acad Sci USA 2006, 103:15582-15587.

17. Ishikawa J, Yamashita A, Mikami Y, Hoshino Y, Kurita H, Hotta K, Shiba T, Hattori M: The complete genomic sequence of Nocardia farcinica IFM 10152. Proc Natl Acad Sci USA 2004, 101:14925-14930.

18. Ikeda M, Nakagawa S: The Corynebacterium glutamicum genome: features and impacts on biotechnological processes. Appl Microbiol Biotechnol 2003, 62:99-109.

19. Nishio Y, Nakamura Y, Kawarabayasi Y, Usuda Y, Kimura E, Sugimoto S, Matsui K, Yamagishi A, Kikuchi H, Ikeo K, Gojobori T: Comparative complete genome sequence analysis of the amino acid replacements responsible for the thermostability of Corynebacterium efficiens. Genome Res 2003, 13:1572-1579.

20. Cerdeno-Tarraga AM, Efstratiou A, Dover LG, Holden MT, Pallen M, Bentley SD, Besra GS, Churcher C, James KD, De Zoysa A, et al: The complete genome sequence and analysis of Corynebacterium diphtheriae NCTC13129. Nucleic Acids Res 2003, 31:6516-6523. 
21. Tauch A, Kaiser O, Hain T, Goesmann A, Weisshaar B, Albersmeier A, Bekel T, Bischoff N, Brune I, Chakraborty T, et al: Complete genome sequence and analysis of the multiresistant nosocomial pathogen Corynebacterium jeikeium K411, a lipid-requiring bacterium of the human skin flora. $J$ Bacteriol 2005, 187:4671-4682.

22. Ikeda H, Ishikawa J, Hanamoto A, Shinose M, Kikuchi H, Shiba T, Sakaki Y, Hattori M, Omura S: Complete genome sequence and comparative analysis of the industrial microorganism Streptomyces avermitilis. Nat Biotechnol 2003, 21:526-531.

23. Bentley SD, Chater KF, Cerdeno-Tarraga AM, Challis GL, Thomson NR, James KD, Harris DE, Quail MA, Kieser H, Harper D, et al: Complete genome sequence of the model actinomycete Streptomyces coelicolor A3(2). Nature 2002, 417:141-147.

24. Barabote RD, Xie G, Leu DH, Normand P, Necsulea A, Daubin V, Medigue C, Adney WS, Xu XC, Lapidus A, et al: Complete genome of the cellulolytic thermophile Acidothermus cellulolyticus $11 \mathrm{~B}$ provides insights into its ecophysiological and evolutionary adaptations. Genome Res 2009, 19:1033-1043.

25. Bruggemann $H$, Henne A, Hoster $F$, Liesegang $H$, Wiezer A, Strittmatter $A$, Hujer S, Durre P, Gottschalk G: The complete genome sequence of Propionibacterium acnes, a commensal of human skin. Science 2004, 305:671-673.

26. Schell MA, Karmirantzou M, Snel B, Vilanova D, Berger B, Pessi G, Zwahlen MC, Desiere F, Bork P, Delley M, et al: The genome sequence of Bifidobacterium longum reflects its adaptation to the human gastrointestinal tract. Proc Natl Acad Sci USA 2002, 99:14422-14427.

27. Wapinski I, Pfeffer A, Friedman N, Regev A: Natural history and evolutionary principles of gene duplication in fungi. Nature 2007, 449:54-61.

28. Wapinski I, Pfeffer A, Friedman N, Regev A: Automatic genome-wide reconstruction of phylogenetic gene trees. Bioinformatics 2007, 23 i549-558.

29. Ashburner M, Ball CA, Blake JA, Botstein D, Butler H, Cherry JM, Davis AP, Dolinski K, Dwight SS, Eppig JT, et al: Gene ontology: tool for the unification of biology. The Gene Ontology Consortium. Nat Genet 2000 25:25-29.

30. Finn RD, Tate J, Mistry J, Coggill PC, Sammut SJ, Hotz HR, Ceric G, Forslund K, Eddy SR, Sonnhammer EL, Bateman A: The Pfam protein families database. Nucleic Acids Res 2008, 36:D281-288.

31. Holder JW, Ulrich JC, DeBono AC, Godfrey PA, Desjardins CA, Zucker J, Zeng Q, Leach AL, Ghiviriga I, Dancel C, Abeel T, Gevers D, Kodira CD, Desany B, Affourtit JP, Birren BW, Sinsky AJ: Comparative and functional genomics of Rhodococcus opacus PD630 for biofuels development. PIOS Genet 2011, 7(9):e1002219.

32. Pandey AK, Sassetti CM: Mycobacterial persistence requires the utilization of host cholesterol. Proc Natl Acad Sci USA 2008, 105:4376-4380.

33. Dzierzewicz Z, Cwalina B, Kurkiewicz S, Chodurek E, Wilczok T: Intraspecies variability of cellular fatty acids among soil and intestinal strains of Desulfovibrio desulfuricans. Appl Environ Microbiol 1996, 62:3360-3365.

34. Takayama K, Wang C, Besra GS: Pathway to synthesis and processing of mycolic acids in Mycobacterium tuberculosis. Clin Microbiol Rev 2005, 18:81-101.

35. Smith S, Witkowski A, Joshi AK: Structural and functional organization of the animal fatty acid synthase. Prog Lipid Res 2003, 42:289-317.

36. Kendall SL, Withers M, Soffair CN, Moreland NJ, Gurcha S, Sidders B, Frita R, ten Bokum A, Besra GS, Lott JS, Stoker NG: A highly conserved transcriptional repressor controls a large regulon involved in lipid degradation in Mycobacterium smegmatis and Mycobacterium tuberculosis. Mol Microbiol 2007, 65:684-699.

37. Van der Geize R, Yam K, Heuser T, Wilbrink MH, Hara H, Anderton MC, Sim E, Dijkhuizen L, Davies JE, Mohn WW, Eltis LD: A gene cluster encoding cholesterol catabolism in a soil actinomycete provides insight into Mycobacterium tuberculosis survival in macrophages. Proc Natl Acad Sci USA 2007, 104:1947-1952.

38. Kendall SL, Burgess P, Balhana R, Withers M, Ten Bokum A, Lott JS, Gao C, Uhia Castro I, Stoker NG: Cholesterol utilisation in mycobacteria is controlled by two TetR-type transcriptional regulators; kstR and kstR2. Microbiology 2010, 156(5):1362-1371.

39. Boshoff HI, Reed MB, Barry CE: Mizrahi V: DnaE2 polymerase contributes to in vivo survival and the emergence of drug resistance in Mycobacterium tuberculosis. Cell 2003, 113:183-193.
40. Ramaswamy S, Musser JM: Molecular genetic basis of antimicrobial agent resistance in Mycobacterium tuberculosis: 1998 update. Tuber Lung Dis 1998, 79:3-29.

41. Espinal MA, Kim SJ, Suarez PG, Kam KM, Khomenko AG, Migliori GB, Baez J, Kochi A, Dye C, Raviglione MC: Standard short-course chemotherapy for drug-resistant tuberculosis: treatment outcomes in 6 countries. JAMA 2000, 283:2537-2545.

42. Mizrahi V, Andersen SJ: DNA repair in Mycobacterium tuberculosis. What have we learnt from the genome sequence? Mol Microbiol 1998, 29:1331-1339.

43. Chan J, Xing Y, Magliozzo RS, Bloom BR: Killing of virulent Mycobacterium tuberculosis by reactive nitrogen intermediates produced by activated murine macrophages. J Exp Med 1992, 175:1111-1122.

44. Nathan C, Shiloh MU: Reactive oxygen and nitrogen intermediates in the relationship between mammalian hosts and microbial pathogens. Proc Natl Acad Sci USA 2000, 97:8841-8848.

45. Warner DF, Ndwandwe DE, Abrahams GL, Kana BD, Machowski EE, Venclovas C, Mizrahi V: Essential roles for imuA'- and imuB-encoded accessory factors in DnaE2-dependent mutagenesis in Mycobacterium tuberculosis. Proc Natl Acad Sci USA 2010, 107:13093-13098.

46. Boshoff HI, Myers TG, Copp BR, McNeil MR, Wilson MA, Barry CE: The transcriptional responses of Mycobacterium tuberculosis to inhibitors of metabolism: novel insights into drug mechanisms of action. J Biol Chem 2004, 279:40174-40184

47. Brooks PC, Movahedzadeh F, Davis EO: Identification of some DNA damage-inducible genes of Mycobacterium tuberculosis: apparent lack of correlation with LexA binding. J Bacteriol 2001, 183:4459-4467.

48. Rand L, Hinds J, Springer B, Sander P, Buxton RS, Davis EO: The majority of inducible DNA repair genes in Mycobacterium tuberculosis are induced independently of RecA. Mol Microbiol 2003, 50:1031-1042.

49. Kana BD, Abrahams GL, Sung N, Warner DF, Gordhan BG, Machowski EE, Tsenova L, Sacchettini JC, Stoker NG, Kaplan G, Mizrahi V: Role of the DinB homologs Rv1537 and Rv3056 in Mycobacterium tuberculosis. J Bacteriol 2010, 192:2220-2227.

50. Williams MJ, Kana BD, Mizrahi V: Functional analysis of molybdopterin biosynthesis in mycobacteria identifies a fused molybdopterin synthase in Mycobacterium tuberculosis. J Bacterio/ 2011, 193:98-106.

51. Schwarz G, Mendel RR, Ribbe MW: Molybdenum cofactors, enzymes and pathways. Nature 2009, 460:839-847.

52. Mehra S, Kaushal D: Functional genomics reveals extended roles of the Mycobacterium tuberculosis stress response factor sigmaH. J Bacteriol 2009, 191:3965-3980.

53. Mendoza-Lopez P, Golby P, Wooff E, Nunez-Garcia J, Garcia-Pelayo MC, Conlon K, Gema-Camacho A, Hewinson RG, Polaina J, Suarez-Garcia A Gordon SV: Characterization of the transcriptional regulator Rv3124 of Mycobacterium tuberculosis identifies it as a positive regulator of molybdopterin biosynthesis and defines the functional consequences of a non-synonymous SNP in the Mycobacterium bovis BCG orthologue. Microbiology 2010, 156:2112-2123.

54. Sekar B, Arunagiri K, Selvakumar N, Preethi KS, Menaka K: Low frequency of moaA3 gene among the clinical isolates of Mycobacterium tuberculosis from Tamil Nadu and Pondicherry-south eastern coastal states of India. BMC Infect Dis 2009, 9:114.

55. Pethe K, Swenson DL, Alonso S, Anderson J, Wang C, Russell DG: Isolation of Mycobacterium tuberculosis mutants defective in the arrest of phagosome maturation. Proc Natl Acad Sci USA 2004, 101:13642-13647.

56. Sassetti CM, Boyd DH, Rubin EJ: Genes required for mycobacterial growth defined by high density mutagenesis. Mol Microbiol 2003, 48:77-84.

57. Tagle DA, Koop BF, Goodman M, Slightom JL, Hess DL, Jones RT: Embryonic epsilon and gamma globin genes of a prosimian primate (Galago crassicaudatus). Nucleotide and amino acid sequences, developmental regulation and phylogenetic footprints. J Mol Biol 1988, 203:439-455.

58. Blanchette M, Tompa M: Discovery of regulatory elements by a computational method for phylogenetic footprinting. Genome Res 2002, 12:739-748.

59. Georg J, Hess WR: cis-antisense RNA, another level of gene regulation in bacteria. Microbiol Mol Biol Rev 2011, 75:286-300, 60.

60. Tezuka T, Hara H, Ohnishi $Y$, Horinouchi S: Identification and gene disruption of small noncoding RNAs in Streptomyces griseus. J Bacteriol 2009, 191:4896-4904 
61. Swiercz JP, Hindra, Bobek J, Haiser HJ, Di Berardo C, Tjaden B, Elliot MA Small non-coding RNAs in Streptomyces coelicolor. Nucleic Acids Res 2008, 36:7240-7251.

62. Arnvig KB, Young DB: Identification of small RNAs in Mycobacterium tuberculosis. Mol Microbiol 2009, 73:397-408

63. DiChiara JM, Contreras-Martinez LM, Livny J, Smith D, McDonough KA Belfort M: Multiple small RNAs identified in Mycobacterium bovis BCG are also expressed in Mycobacterium tuberculosis and Mycobacterium smegmatis. Nucleic Acids Res 2010, 38:4067-4078.

64. Abeel T, Van-Parys T, Saeys Y, Galagan J, Van-de-Peer Y: GenomeView: a next-generation genome browser. Nucleic Acids Res 2012, 2:e12.

65. Prabhakar S, Poulin F, Shoukry M, Afzal V, Rubin EM, Couronne O Pennacchio LA: Close sequence comparisons are sufficient to identify human cis-regulatory elements. Genome Res 2006, 16:855-863.

66. Pedersen JS, Bejerano G, Siepel A, Rosenbloom K, Lindblad-Toh K, Lander ES, Kent J, Miller W, Haussler D: Identification and classification of conserved RNA secondary structures in the human genome. PLOS Comput Biol 2006, 2:e33.

67. Park HD, Guinn KM, Harrell MI, Liao R, Voskuil MI, Tompa M, Schoolnik GK, Sherman DR: Rv3133c/dosR is a transcription factor that mediates the hypoxic response of Mycobacterium tuberculosis. Mol Microbiol 2003, 48:833-843.

68. Prakash P, Yellaboina S, Ranjan A, Hasnain SE: Computational prediction and experimental verification of novel IdeR binding sites in the upstream sequences of Mycobacterium tuberculosis open reading frames. Bioinformatics 2005, 21:2161-2166.

69. Maciag A, Dainese E, Rodriguez GM, Milano A, Provvedi R, Pasca MR, Smith I, Palu G, Riccardi G, Manganelli R: Global analysis of the Mycobacterium tuberculosis Zur (FurB) regulon. J Bacterio/ 2007, 189:730-740

70. Bai G, McCue LA, McDonough KA: Characterization of Mycobacterium tuberculosis Rv3676 (CRPMt), a cyclic AMP receptor protein-like DNA binding protein. J Bacterio/ 2005, 187:7795-7804

71. Liu T, Ramesh A, Ma Z, Ward SK, Zhang L, George GN, Talaat AM, Sacchettini JC, Giedroc DP: CsoR is a novel Mycobacterium tuberculosis copper-sensing transcriptional regulator. Nat Chem Biol 2007, 3:60-68.

72. Sala C, Forti F, Di Florio E, Canneva F, Milano A, Riccardi G, Ghisotti D: Mycobacterium tuberculosis FurA autoregulates its own expression. $J$ Bacteriol 2003, 185:5357-5362.

73. He H, Hovey R, Kane J, Singh V, Zahrt TC: MprAB is a stress-responsive two-component system that directly regulates expression of sigma factors SigB and SigE in Mycobacterium tuberculosis. J Bacterio/ 2006 188:2134-2143

74. Florczyk MA, McCue LA, Purkayastha A, Currenti E, Wolin MJ, McDonough KA: A family of acr-coregulated Mycobacterium tuberculosis genes shares a common DNA motif and requires Rv3133c (dosR or devR) for expression. Infect Immun 2003, 71:5332-5343.

75. Reddy TB, Riley R, Wymore F, Montgomery P, Decaprio D, Engels R, Gellesch M, Hubble J, Jen D, Jin H, et al: TB database: an integrated platform for tuberculosis research. Nucleic Acids Res 2008, 37:D499-508.

76. Hughes JD, Estep PW, Tavazoie S, Church GM: Computational identification of cis-regulatory elements associated with groups of functionally related genes in Saccharomyces cerevisiae. $J \mathrm{Mol}$ Biol 2000 296:1205-1214

77. McGuire AM, Hughes JD, Church GM: Conservation of DNA regulatory motifs and discovery of new motifs in microbial genomes. Genome Res 2000, 10:744-757

78. Schneider TD, Stephens RM: Sequence logos: a new way to display consensus sequences. Nucleic Acids Res 1990, 18:6097-6100.

79. Veyrier FJ, Dufort A, Behr MA: The rise and fall of the Mycobacterium tuberculosis genome. Trends Microbiol 2011, 19(4):156-161.

80. Veyrier F, Pletzer D, Turenne C, Behr MA: Phylogenetic detection of horizontal gene transfer during the step-wise genesis of Mycobacterium tuberculosis. BMC Evol Biol 2009, 9:196.

81. Gamieldien J, Ptitsyn A, Hide W: Eukaryotic genes in Mycobacterium tuberculosis could have a role in pathogenesis and immunomodulation. Trends Genet 2002, 18:5-8.

82. Marri PR, Bannantine JP, Paustian ML, Golding GB: Lateral gene transfer in Mycobacterium avium subspecies paratuberculosis. Can J Microbiol 2006, 52:560-569.
83. Rosas-Magallanes V, Deschavanne P, Quintana-Murci L, Brosch R, Gicquel B, Neyrolles O: Horizontal transfer of a virulence operon to the ancestor of Mycobacterium tuberculosis. Mol Biol Evol 2006, 23:1129-1135.

84. Kinsella RJ, Fitzpatrick DA, Creevey CJ, McInerney JO: Fatty acid biosynthesis in Mycobacterium tuberculosis: lateral gene transfer, adaptive evolution, and gene duplication. Proc Natl Acad Sci USA 2003, 100:10320-10325.

85. Smith NH, Dale J, Inwald J, Palmer S, Gordon SV, Hewinson RG, Smith JM: The population structure of Mycobacterium bovis in Great Britain: clonal expansion. Proc Natl Acad Sci USA 2003, 100:15271-15275.

86. Supply P, Warren RM, Banuls AL, Lesjean S, Van Der Spuy GD, Lewis LA, Tibayrenc M, Van Helden PD, Locht C: Linkage disequilibrium between minisatellite loci supports clonal evolution of Mycobacterium tuberculosis in a high tuberculosis incidence area. Mol Microbiol 2003 47:529-538.

87. Tuberculosis Systems Biology Website. [http://www.broadinstitute.org/ annotation/tbsysbio]

88. Thompson JD, Higgins DG, Gibson TJ: CLUSTAL W: improving the sensitivity of progressive multiple sequence alignment through sequence weighting, position-specific gap penalties and weight matrix choice. Nucleic Acids Res 1994, 22:4673-4680

89. Felsenstein J: PHYLIP - Phylogeny Inference Package. Cladistics 1989, 5:164-166

90. Tian W, Arakaki AK, Skolnick J: EFICAz: a comprehensive approach for accurate genome-scale enzyme function inference. Nucleic Acids Res 2004 32:6226-6239.

91. Karp PD, Paley SM, Krummenacker M, Latendresse M, Dale JM, Lee TJ, Kaipa P, Gilham F, Spaulding A, Popescu L, et al: Pathway Tools version 13.0: integrated software for pathway/genome informatics and systems biology. Brief Bioinform 2010, 11:40-79.

92. Karp PD, Ouzounis CA, Moore-Kochlacs C, Goldovsky L, Kaipa P, Ahren D, Tsoka S, Darzentas N, Kunin V, Lopez-Bigas N: Expansion of the BioCyc collection of pathway/genome databases to 160 genomes. Nucleic Acids Res 2005, 33:6083-6089.

93. Conesa A, Gotz S, Garcia-Gomez JM, Terol J, Talon M, Robles M: Blast2GO: a universal tool for annotation, visualization and analysis in functional genomics research. Bioinformatics 2005, 21:3674-3676.

94. Pellegrini M, Marcotte EM, Thompson MJ, Eisenberg D, Yeates TO: Assigning protein functions by comparative genome analysis: protein phylogenetic profiles. Proc Natl Acad Sci USA 1999, 96:4285-4288

95. Shaffer JP: Multiple Hypothesis Testing. Annu Rev Psychol 1995, 46:561-584.

96. Perneger TV: What's wrong with Bonferroni adjustments. BMJ 1998, 316:1236-1238

97. Roth FP, Hughes JD, Estep PW, Church GM: Finding DNA regulatory motifs within unaligned noncoding sequences clustered by whole-genome mRNA quantitation. Nat Biotechnol 1998, 16:939-945

98. Robison K, McGuire AM, Church GM: A comprehensive library of DNAbinding site matrices for 55 proteins applied to the complete Escherichia coli K-12 genome. J Mol Biol 1998, 284:241-254.

99. Baumbach J: CoryneRegNet 4.0 - A reference database for corynebacterial gene regulatory networks. BMC Bioinformatics 2007, 8:429.

100. Zhang J, Nielsen R, Yang Z: Evaluation of an improved branch-site likelihood method for detecting positive selection at the molecular level. Mol Biol Evol 2005, 22:2472-2479.

101. Yang Z: PAML 4: phylogenetic analysis by maximum likelihood. $\mathrm{Mol}$ Biol Evol 2007, 24:1586-1591.

102. Goldman N, Yang Z: A codon-based model of nucleotide substitution for protein-coding DNA sequences. Mol Biol Evol 1994, 11:725-736.

103. Yang Z: Likelihood ratio tests for detecting positive selection and application to primate lysozyme evolution. Mol Biol Evol 1998, 15:568-573.

104. Yang Z, Nielsen R, Hasegawa M: Models of amino acid substitution and applications to mitochondrial protein evolution. Mol Biol Evol 1998, 15:1600-1611.

105. Ma B, Tromp J, Li M: PatternHunter: faster and more sensitive homology search. Bioinformatics 2002, 18:440-445.

106. Brudno M, Do CB, Cooper GM, Kim MF, Davydov E, Green ED, Sidow A, Batzoglou S: LAGAN and Multi-LAGAN: efficient tools for large-scale multiple alignment of genomic DNA. Genome Res 2003, 13:721-731.

107. Ruzzo WL, Tompa M: A linear time algorithm for finding all maximal scoring subsequences. Proc Int Conf Intell Syst Mol Biol 1999, 1999:234-241. 
108. Mortazavi A, Williams BA, McCue K, Schaeffer L, Wold B: Mapping and quantifying mammalian transcriptomes by RNA-Seq. Nat Methods 2008, 5:621-628

109. Raman S, Puyang X, Cheng TY, Young DC, Moody DB, Husson RN: Mycobacterium tuberculosis SigM positively regulates Esx secreted protein and nonribosomal peptide synthetase genes and down regulates virulence-associated surface lipid synthesis. J Bacteriol 2006, 188:8460-8468

110. Rocha EP, Smith JM, Hurst LD, Holden MT, Cooper JE, Smith NH, Feil EJ: Comparisons of $\mathrm{dN} / \mathrm{dS}$ are time dependent for closely related bacterial genomes. J Theor Biol 2006, 239:226-235.

111. Turenne CY, Collins DM, Alexander DC, Behr MA: Mycobacterium avium subsp. paratuberculosis and M. avium subsp. avium are independently evolved pathogenic clones of a much broader group of $\mathrm{M}$. avium organisms. J Bacteriol 2008, 190:2479-2487.

112. Voskuil MI, Schnappinger D, Rutherford R, Liu Y, Schoolnik GK: Regulation of the Mycobacterium tuberculosis PE/PPE genes. Tuberculosis (Edinb) 2004, 84:256-262.

113. Fleischmann RD, Alland D, Eisen JA, Carpenter L, White O, Peterson J, DeBoy R, Dodson R, Gwinn M, Haft D, et al: Whole-genome comparison of Mycobacterium tuberculosis clinical and laboratory strains. J Bacteriol 2002, 184:5479-5490

114. Hershberg R, Lipatov M, Small PM, Sheffer H, Niemann S, Homolka S, Roach JC, Kremer K, Petrov DA, Feldman MW, Gagneux S: High functional diversity in Mycobacterium tuberculosis driven by genetic drift and human demography. PLOS Biol 2008, 6:e311.

115. Ramage HR, Connolly LE, Cox JS: Comprehensive functional analysis of Mycobacterium tuberculosis toxin-antitoxin systems: implications for pathogenesis, stress responses, and evolution. PLoS Genet 2009, 5 : e1000767.

116. Anantharaman $\mathrm{V}$, Aravind L: New connections in the prokaryotic toxinantitoxin network: relationship with the eukaryotic nonsense-mediated RNA decay system. Genome Biol 2003, 4:R81.

117. Pallen MJ: The ESAT-6/WXG100 superfamily - and a new Gram-positive secretion system? Trends Microbiol 2002, 10:209-212.

118. Gey van-Pittius NC, Sampson SL, Lee H, Kim Y, van Helden PD, Warren RM: Evolution and expansion of the Mycobacterium tuberculosis PE and PPE multigene families and their association with the duplication of the ESAT-6 (esx) gene cluster regions. BMC Evol Biol 2006, 6:95.

119. Gioffre A, Infante E, Aguilar D, Santangelo MP, Klepp L, Amadio A, Meikle V, Etchechoury I, Romano Ml, Cataldi A, et al: Mutation in mce operons attenuates Mycobacterium tuberculosis virulence. Microbes Infect 2005 7:325-334

120. Casali N, Riley LW: A phylogenomic analysis of the Actinomycetales mce operons. BMC Genomics 2007, 8:60.

121. Sulzenbacher G, Canaan S, Bordat Y, Neyrolles O, Stadthagen G, RoigZamboni V, Rauzier J, Maurin D, Laval F, Daffe M, et al: LppX is a lipoprotein required for the translocation of phthiocerol dimycocerosates to the surface of Mycobacterium tuberculosis. EMBO 2006, 25:1436-1444.

122. Astarie-Dequeker C, Le Guyader L, Malaga W, Seaphanh FK, Chalut C, Lopez A, Guilhot C: Phthiocerol dimycocerosates of M. tuberculosis participate in macrophage invasion by inducing changes in the organization of plasma membrane lipids. PLoS Pathog 2009, 5:e1000289.

123. Rousseau C, Winter N, Pivert E, Bordat Y, Neyrolles O, Ave P, Huerre M, Gicquel B, Jackson M: Production of phthiocerol dimycocerosates protects Mycobacterium tuberculosis from the cidal activity of reactive nitrogen intermediates produced by macrophages and modulates the early immune response to infection. Cell Microbiol 2004, 6:277-287.

124. Brulle JK, Grau T, Tschumi A, Auchli Y, Burri R, Polsfuss S, Keller PM, Hunziker P, Sander P: Cloning, expression and characterization of Mycobacterium tuberculosis lipoprotein LprF. Biochem Biophys Res Commun 2010, 391:679-684.

125. Pecora ND, Gehring AJ, Canaday DH, Boom WH, Harding CV: Mycobacterium tuberculosis LprA is a lipoprotein agonist of TLR2 that regulates innate immunity and APC function. J Immunol 2006, 177:422-429

126. Vetting MW, Hegde SS, Fajardo JE, Fiser A, Roderick SL, Takiff HE, Blanchard JS: Pentapeptide repeat proteins. Biochemistry 2006, 45:1-10.

127. Molina N, van Nimwegen E: Scaling laws in functional genome content across prokaryotic clades and lifestyles. Trends Genet 2009, 25:243-247.
128. van Nimwegen E: Scaling laws in the functional content of genomes. Trends Genet 2003, 19:479-484.

129. Cases I, de Lorenzo V, Ouzounis CA: Transcription regulation and environmental adaptation in bacteria. Trends Microbiol 2003, 11:248-253.

130. Konstantinidis KT, Tiedje JM: Trends between gene content and genome size in prokaryotic species with larger genomes. Proc Natl Acad Sci USA 2004, 101:3160-3165.

doi:10.1186/1471-2164-13-120

Cite this article as: McGuire et al:: Comparative analysis of Mycobacterium and related Actinomycetes yields insight into the evolution of Mycobacterium tuberculosis pathogenesis. BMC Genomics 2012 13:120.

\section{Submit your next manuscript to BioMed Central and take full advantage of:}

- Convenient online submission

- Thorough peer review

- No space constraints or color figure charges

- Immediate publication on acceptance

- Inclusion in PubMed, CAS, Scopus and Google Scholar

- Research which is freely available for redistribution

Submit your manuscript at www.biomedcentral.com/submit
C) Biomed Central 